\title{
Cooperative structure of the heterotrimeric pre-mRNA retention and splicing complex
}

\author{
Piotr Wysoczański ${ }^{1}$, Cornelius Schneider ${ }^{2}$, ShengQi Xiang ${ }^{1}$, Francesca Munari ${ }^{1}$, Simon Trowitzsch ${ }^{2,6}$, \\ Markus C Wahl ${ }^{3}$, Reinhard Lührmann², Stefan Becker ${ }^{1}$ \& Markus Zweckstetter ${ }^{1,4,5}$
}

The precursor mRNA (pre-mRNA) retention and splicing (RES) complex is a spliceosomal complex that is present in yeast and humans and is important for RNA splicing and retention of unspliced pre-mRNA. Here, we present the solution NMR structure of the RES core complex from Saccharomyces cerevisiae. Complex formation leads to an intricate folding of three componentsSnu17p, Bud13p and Pml1p-that stabilizes the RNA-recognition motif (RRM) fold of Snu17p and increases binding affinity in tertiary interactions between the components by more than $\mathbf{1 0 0}$-fold compared to that in binary interactions. RES interacts with pre-mRNA within the spliceosome, and through the assembly of the RES core complex RNA binding efficiency is increased. The three-dimensional structure of the RES core complex highlights the importance of cooperative folding and binding in the functional organization of the spliceosome.

Splicing entails the removal of introns from pre-mRNAs to generate exon-only mRNA, which is exported out of the nucleus for translation ${ }^{1}$. The splicing process is driven and controlled by a large and dynamic RNA-protein complex, the spliceosome ${ }^{1,2}$. The composition and structure of the spliceosome undergoes multiple rearrangements during a splicing reaction, in which a set of distinct structural and compositional states, designated as $\mathrm{E}, \mathrm{A}, \mathrm{B}^{\text {act }}, \mathrm{B}^{\star}$ and $\mathrm{C}$ complexes, can be defined ${ }^{1}$. As part of this process, small nuclear ribonucleoprotein (snRNP) particles and non-snRNP splice factors are recruited and released ${ }^{1,2}$. Although the organization of snRNP components of the spliceosome has received considerable attention in recent years, very little is known about the assembly, structure and dynamics of non-snRNP multimeric complexes.

The non-snRNP RES complex is present in humans and yeast ${ }^{3,4}$. Deletion of RES genes slows splicing and leads to pre-mRNA leakage into the cytoplasm ${ }^{3-5}$. Distinct introns exhibit RES-dependent splicing $^{5-9}$, as do pre-mRNAs encoding proteins functioning in RNA-nucleotide metabolism ${ }^{8,10}$. Components of the RES complex are found in B and C complexes of the spliceosome, in which RES can interact with $\mathrm{U} 2 \mathrm{snRNP}{ }^{4,11,12}$. In yeast, the RES complex is composed of three proteins, snRNP-associated protein 17 (Snu17p, also known as Ist3p), pre-mRNA-leakage protein 1 (Pml1p) and bud siteselection protein $13(\operatorname{Bud} 13 p)^{3,4}$. Snu17p and Bud13p have been implicated directly in splicing $3,5,13$, whereas Pml1p has been linked to the retention of unspliced pre-mRNA in the nucleus ${ }^{3,5}$. Caenorhabditis elegans Bud13p is involved in embryogenesis ${ }^{14}$.
Sequence analysis has indicated that Snu17p is a 148-residue (17.1-kDa) noncanonical member of the RRM family of proteins with a long C-terminal part, which exhibits low sequence similarity to published RRM structures ${ }^{4}$. Snu17p binds with nanomolar affinity to the 266 -residue $(30.5-\mathrm{kDa})$, natively disordered protein Bud13 $\mathrm{p}^{15}$. The interaction has been postulated to involve a C-terminal UHM-ligand motif (ULM) in Bud13p that interacts with a U2AF-homology motif (UHM) in the RRM domain of Snu17p $\mathrm{p}^{13,15,16}$. The only other identified domain encompasses a stretch of lysine residues at the $\mathrm{N}$ terminus of Bud13p. Binding of the third component, the 204-residue (23.4-kDa) Pmllp, occurs through its $50 \mathrm{~N}$-terminal disordered residues. The remainder of Pmllp folds as a forkhead-associated domain ${ }^{13,15,17}$, which could potentially bind phosphopeptides ${ }^{17}$. Biochemical evidence has suggested that Snu17p acts as the central binding platform, which interacts with disordered parts of Bud13p and Pml1p ${ }^{13,15,16}$. The precise molecular architecture of the RES complex, however, has been elusive, and its RNA binding capabilities have remained unexplored.

Here we solved the three-dimensional structure of the core of the RES complex and demonstrated that its assembly is driven by cooperativity that increases the binding affinity of the components of the complex by more than 100 -fold. We further showed that the RES complex directly contacts pre-mRNA in the spliceosome and interacts with the intron between the branch point and 3' splice site. RNA binding was supported by the cooperative assembly of the RES complex, thus highlighting the importance of cooperative folding in the spliceosome.

${ }^{1}$ Department for NMR-based Structural Biology, Max Planck Institute for Biophysical Chemistry, Göttingen, Germany. ${ }^{2}$ Department of Cellular Biochemistry,

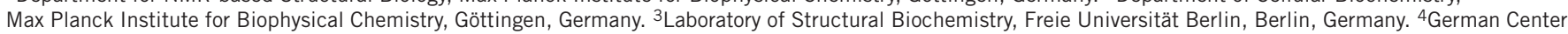
for Neurodegenerative Diseases (DZNE), Göttingen, Germany. ${ }^{5}$ Center for Nanoscale Microscopy and Molecular Physiology of the Brain, University Medical Center, Göttingen, Germany. ${ }^{6}$ Present address: European Molecular Biology Laboratory, Grenoble Outstation, Grenoble, France, and Unit for Virus Host-Cell Interactions, Université Grenoble Alpes-European Molecular Biology Laboratory-National Center for Scientific Research, Grenoble, France. Correspondence should be addressed to M.Z. (markus.zweckstetter@dzne.de). 


\begin{tabular}{|c|c|c|c|c|c|}
\hline Titrant & Analyte (+ & (cSnu17p) & $-T \Delta S(\mathrm{~K} \times \mathrm{kcal} / \mathrm{mol})$ & $\Delta H(\mathrm{kcal} / \mathrm{mol})$ & $K_{\mathrm{d}}(\mathrm{nM})$ \\
\hline \multirow[t]{5}{*}{ cPml1pWT } & & & $9.1 \pm 0.5$ & $-16.7 \pm 0.5$ & $1,328 \pm 138$ \\
\hline & - & ${ }^{c}$ Bud13pwT & $16.2 \pm 0.4$ & $-26.7 \pm 0.3$ & $7.8 \pm 2.6$ \\
\hline & - & 'Bud13pw232A & $40.9 \pm 0.8$ & $-50.8 \pm 0.9$ & $25.6 \pm 5.3$ \\
\hline & - & cBud13pV235A & $16.3 \pm 1.4$ & $-26.7 \pm 1.2$ & $9.6 \pm 0.3$ \\
\hline & - & ${ }^{C}$ Bud13pR231A & $10.8 \pm 0.1$ & $-20.4 \pm 0.1$ & $39.2 \pm 0.3$ \\
\hline \multirow{4}{*}{${ }^{c P m l 1} p^{F 32 A}$} & - & - & NB & NB & NB \\
\hline & & 'Bud13pWT & $9.1 \pm 0.6$ & $-16.0 \pm 0.6$ & $4,732 \pm 697$ \\
\hline & & ${ }^{\mathrm{C} B u d} 13 p^{\mathrm{R} 231 \mathrm{~A}}$ & NB & NB & NB \\
\hline & & 'Bud13pw232A & B & B & B \\
\hline \multirow[t]{2}{*}{${ }^{c} P m l 1 p^{L 38 A}$} & - & - & $>5.9^{a}$ & $>-11.2^{\mathrm{a}}$ & $>83,333^{a}$ \\
\hline & & 'Bud13pWT & $9.7 \pm 0.6$ & $-18.3 \pm 0.4$ & $196.3 \pm 83.3$ \\
\hline \multirow[t]{2}{*}{ 'Bud13pwT } & - & - & $17.2 \pm 0.3$ & $-27.2 \pm 0.3$ & $17.7 \pm 1.1$ \\
\hline & cPml1pWT & - & $<28.0 \pm 0.3$ & $<-38.1 \pm 0.3$ & $<13.8 \pm 0.9$ \\
\hline \multirow[t]{2}{*}{ 'Bud13pR231A } & - & - & $18.8 \pm 1.7$ & $-28.6 \pm 2.0$ & $22.3 \pm 10.8$ \\
\hline & cPml1pwT & - & $23.2 \pm 0.3$ & $-33.9 \pm 0.1$ & $5.3 \pm 0.3$ \\
\hline \multirow[t]{2}{*}{ 'Bud13pw232A } & - & - & NB & NB & NB \\
\hline & cPml1pWT & - & $15.0 \pm 0.7$ & $-22.7 \pm 0.8$ & $956.5 \pm 231.1$ \\
\hline \multirow[t]{2}{*}{ cBud13pV235A } & - & - & $9.9 \pm 0.3$ & $-18.1 \pm 0.3$ & $401.4 \pm 22.6$ \\
\hline & ${ }^{c P m l 1 p W T}$ & - & 20.1 & $-29.3 \pm 0.3$ & $79.4 \pm 1.3$ \\
\hline \multirow[t]{2}{*}{ 'Bud13p $p^{R 237 A}$} & - & - & NB & NB & NB \\
\hline & ${ }^{\mathrm{c} P m l 1 p^{W T}}$ & - & B & B & B \\
\hline \multirow[t]{2}{*}{ 'Bud13p F224A } & - & - & $10.8 \pm 0.1$ & $-19.4 \pm 0.1$ & $210.7 \pm 5.8$ \\
\hline & cPml1pwT & - & $17.0 \pm 0.1$ & $-27.1 \pm 0.2$ & $12.9 \pm 1.0$ \\
\hline
\end{tabular}

NB, no binding; $B$, binding detected but not quantifiable. Errors were estimated as the difference between maximum and minimum values of the measurements.

aEstimated lower limit for the parameters.

\section{RESULTS}

\section{Structure of the RES core complex}

To precisely define the Snu17p-binding regions of Bud13p and Pml1p, we monitored binding of GST-Snu17p fusion protein to peptide arrays that covered residues 200-266 of Bud13p and residues 1-60 of Pml1p. These regions bind to residues $25-138$ of Snu17 $p^{15}$. GST-Snu $17 \mathrm{p}$ binding was centered on residues 215-245 of Bud13p and residues 22-42 of Pmllp. Isothermal titration calorimetry (ITC) analyses showed that synthetic peptides Bud13p(215-245) and Pml1p(22-42) bound to Snu17p(25-138) with affinities of $17.2 \pm 0.3 \mathrm{nM}$ and 1,328 $\pm 138 \mathrm{nM}$, respectively (Table $\mathbf{1}$ ). The affinities are comparable to those of the full-length proteins ${ }^{15}$. Thus, residues 215 to 245 of Bud13p (core Bud13p, ${ }^{\mathrm{C} B u d 13 p}$ ) and residues 22-42 of Pml1p (core Pml1p, ${ }^{\mathrm{CPml}}$ (p) represent the minimal regions required for binding to residues 25-138 of Snu17p (core Snu17p, ' Snu 17p).

Next, we studied the interaction between ${ }^{\mathrm{c} S n u} 17 \mathrm{p},{ }^{\mathrm{c} B u d 13 p}$ and 'Pmllp by using NMR spectroscopy (Supplementary Fig. 1). Binding of disordered ${ }^{\mathrm{C} B u d 13 p}$ (Supplementary Fig. 1e) to ${ }^{\mathrm{C} S n u 17 p}$ was slow on the NMR time scale and saturated at a molar ratio of 1:1. Addition of disordered ${ }^{\mathrm{C}} \mathrm{Pmllp}$ (Supplementary Fig. 1f) induced further chemical-shift changes that saturated at a molar ratio of 1:1. Using a wide variety of multidimensional NMR experiments, we achieved the sequence-specific assignment of the backbone and side chain resonances $\left(96.7 \%\right.$ of all ${ }^{1} \mathrm{H}$ resonances). We collected a large number of unambiguous intraprotein $(3,541)$ as well as intermolecular

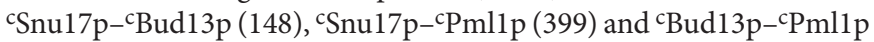
(17) NOE distance restraints. They defined the structure of the RES core complex at high resolution (r.m.s. deviation (r.m.s.d.) of $0.97 \AA$ for all heavy atoms; Fig. 1a and Table 2). We cross-validated the structure by $\mathrm{HN}$ and $\mathrm{NCO}$ residual dipolar couplings (RDCs), which resulted in good agreement between experimental and back-calculated RDCs (quality factor, $Q_{\text {avg }}=0.31$; Pearson's linear correlation coefficient, $R_{\text {avg }}=0.911$; Supplementary Fig. 2). In addition, it was possible to refine the structure in the presence of RDCs to $Q_{\mathrm{avg}}=$ 0.04 and $R_{\text {avg }}=0.997$ (Supplementary Fig. 2), with an r.m.s.d. of the structure before and after refinement of $0.74 \AA(0.53 \AA)$ for all heavy atoms (backbone atoms; residues 30 130 of $^{\mathrm{C} S}$ nu $17 \mathrm{p}$, residues $26-42$ of $^{\mathrm{C} P m l 1 p}$ and residues 222-239 of ${ }^{\mathrm{c}} \mathrm{Bud} 13 \mathrm{p}$ ).

In the complex, 'Snu17p adopts the $\beta 1-\alpha 1-$ $\beta 2-\beta 3-\alpha 2-\beta 4$ topology of RRMs (Fig. 1a,b). $\mathrm{C}$ terminal to the RRM fold, residues Q116 to V131 fold into an $\alpha$-helix $(\alpha 3)$ that packs against $\alpha$-helix 1 and $\beta$-strand 2 (Figs. 1a,b and $2 \mathbf{a}, \mathbf{b}) . \alpha 3$ is connected to the remainder of the protein via a loop, which traverses the middle of the $\beta$-sheet perpendicularly (Fig. 1b). ${ }^{\mathrm{C}} \mathrm{Pml}$ lp and ${ }^{\mathrm{C}} \mathrm{Bud} 13 \mathrm{p}$ bind on the opposite side of the $\beta$-sheet (Fig. 1b). Residues I27 to S35 of ${ }^{\mathrm{c} P m l 1 p}$ bind in an extended conformation in parallel to $\alpha 3$, providing an intermolecular attachment site for the C-terminal $\alpha$-helix ( $\alpha 3)$ of ${ }^{c}$ Snu $17 p$, followed by a short $\alpha$-helix that attaches to a

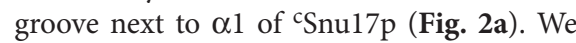
found few direct contacts between $\alpha 3$ and the remainder of ${ }^{\mathrm{C}} \mathrm{Snu} 17 \mathrm{p}$ as well as ${ }^{\mathrm{c}} \mathrm{Bud} 13 \mathrm{p}$, results suggesting that it is primarily ${ }^{\mathrm{C}} \mathrm{Pmllp}$ that mediates the folding of $\alpha 3$ in RES. The ${ }^{\mathrm{C} P m l 1 p}{ }^{\mathrm{c}}$ Snu $17 \mathrm{p}$ interaction is mostly hydrophobic, with the three ${ }^{\mathrm{C} P m l 1}$ p residues $\mathrm{F} 32, \mathrm{~L} 37$ and L38 located in the center of the interaction interface (Fig. 2a,c).

${ }^{c} \mathrm{Bud} 13 \mathrm{p}$ forms an extended hairpin structure and occupies a large and flat binding site provided by $\alpha$-helices 1 and 2 of ${ }^{\mathrm{C} S n u} 17 \mathrm{p}$, in proximity to the $\alpha$-helix of ${ }^{\mathrm{C}} \mathrm{Pml} 1 \mathrm{p}$ (Figs. 1a and $\mathbf{2 b}$ ). In canonical UHM-ULM interactions, the ULM is formed by a positively charged sequence followed by an essential tryptophan ${ }^{18-22}$. In Bud13p the tryptophan is located at position 232 , and it was supposed to bind to the hydrophobic pocket between $\alpha$-helices 1 and 2 (refs. 15,16). In the structure of the RES core complex, however, this site is

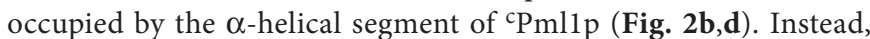
W232 is positioned above E53 of ${ }^{\mathrm{c} S n u 17 p}$ (Fig. 2b,d). A potential repulsion due to the proximity to the negatively charged E53

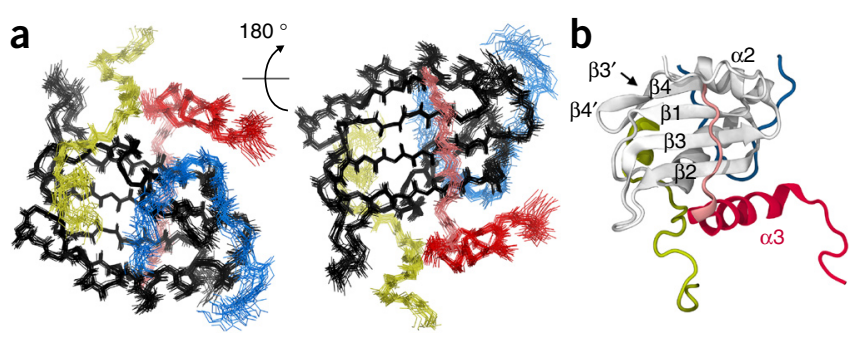

Figure 1 Three-dimensional structure of the RES core complex. (a) Ensemble of the 20 lowest-energy structures, showing backbone atoms only. Yellow, 'Pml1p; blue, 'Bud13p; red, C-terminal $\alpha$-helix of 'Snu17p; pink, connecting loop; black, body of the RRM of Snu17p. (b) View of the $\beta$-sheets (gray) of ${ }^{\mathrm{c}}$ Snu17p in ${ }^{\mathrm{C}} \mathrm{RES}$, with additional color coding as in a. 
Table 2 NMR and refinement statistics

cSnu17p

cPml1p

cBud13p

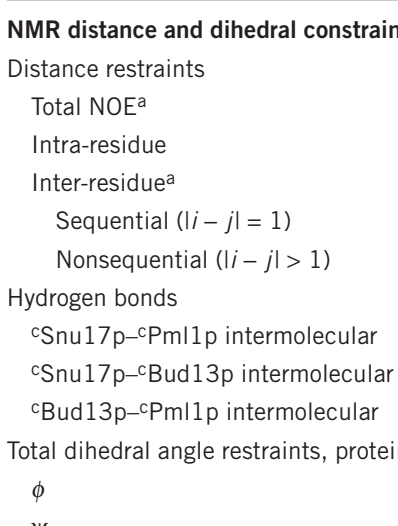

Structure statistics

Violations (mean \pm s.d. $)^{\mathrm{b}}$

Distance constraints ( $\AA$ )

Dihedral angle constraints $\left({ }^{\circ}\right)$

Max. dihedral angle violation $\left(^{\circ}\right)$

Max. distance constraint violation ( $\AA$ )

Deviations from idealized geometry ${ }^{b}$

Bond lengths $(\AA)$

Bond angles $\left({ }^{\circ}\right)$

Impropers $\left({ }^{\circ}\right)$

Average pairwise r.m.s. deviation, protein $(\AA)^{\mathrm{c}}$

Heavy

Backbone

Complex

All complex heavy (C, N, O, P)

$\begin{array}{ccc}2,767 & 417 & 357 \\ 542 & 117 & 110 \\ 2,225 & 300 & 247 \\ 645 & 181 & 138 \\ 1,580 & 119 & 109 \\ 50 & - & - \\ 399 & 399 & - \\ 148 & - & 148 \\ - & 17 & 17 \\ 91 & & \\ 91 & 8 & 16 \\ & 8 & 16\end{array}$

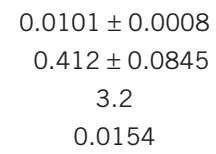

0.0154

$0.0108 \pm 0.00026$

$1.24 \pm 0.023$

$1.52 \pm 0.048$

$0.94 \pm 0.09$

$0.78 \pm 0.13$

$1.38 \pm 0.23$

$0.50 \pm 0.05$

$0.49 \pm 0.12$

$0.66 \pm 0.13$

anly intramolecular NOEs are counted. ${ }^{b}$ Calculated over all residues among 20 refined structures. ${ }^{c}$ Pairwise r.m.s.d. calculated among 20 refined structures over residues 10-110 ('Snu17p), 26-42 (cPml1p) and 224-237 ('Bud13p).

is avoided by formation of a salt bridge between E53 and the evolutionarily conserved R237 of ${ }^{\mathrm{c} B u d 13 p}$ (Fig. 2d,e).

\section{RES assembly is highly cooperative}

We investigated the thermodynamics of RES-complex assembly by ITC. In agreement with previous studies ${ }^{15,16}$, ${ }^{\mathrm{c} B u d} 13 \mathrm{p}$ bound to monomeric ${ }^{\mathrm{c} S n u} 17 \mathrm{p}$ with nanomolar affinity (Table 1). Moreover,
${ }^{\mathrm{C} B u d 13 p}$ bound to a preassembled ${ }^{\mathrm{c} S n u 17 p-}$ ${ }^{c}$ Pmllp dimer with similar affinity (Table 1). In contrast, when we added ${ }^{\mathrm{C}} \mathrm{Pml} 1 \mathrm{p}$ to a ${ }^{c}$ Snu $17 p-{ }^{c}$ Bud13p dimer, the interaction was highly cooperative (Fig. 3a,b and Table 1):

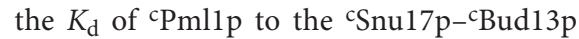
dimer was $7.8 \pm 0.3 \mathrm{nM}$, i.e., more than two orders of magnitude lower than that observed for binding of ${ }^{\mathrm{C}} \mathrm{Pmllp}$ to ${ }^{\mathrm{c} S} \mathrm{Su} 17 \mathrm{p}$ alone.

Next, we replaced residues that form intermolecular contacts in the RES core complex (F224, R231, W232, R237 and V235 on ${ }^{\mathrm{C} B u d 13 p ; ~ F 32 ~ a n d ~ L 38 ~ o n ~}{ }^{\mathrm{C} P m l 1 p}$; Fig. $2 \mathbf{c}-\mathbf{e})$ by alanine. With the exception of ${ }^{\mathrm{C}} \mathrm{Bud} 13 \mathrm{p}^{\mathrm{R} 231 \mathrm{~A}}$, the mutations strongly destabilized the interaction of ${ }^{\mathrm{c}} \mathrm{Bud} 13 \mathrm{p}$ and ${ }^{\mathrm{C}}$ Pmllp to monomeric ${ }^{\mathrm{C} S}$ nu $17 \mathrm{p}$ (Table 1). ${ }^{\mathrm{C} B u d} 13 \mathrm{p}^{\mathrm{W} 232 \mathrm{~A}},{ }^{\mathrm{C}} \mathrm{Bud} 13 \mathrm{p}^{\mathrm{R} 237 \mathrm{~A}}$ and ${ }^{\mathrm{C}} \mathrm{Pml} 1 \mathrm{p}^{\mathrm{F} 32 \mathrm{~A}}$ even completely abolished binding (Table $\mathbf{1}$ ). However, when we tested the mutants for interaction with ${ }^{\mathrm{C}}$ Snu $17 \mathrm{p}-{ }^{\mathrm{c} P m l 1 p}$ and the ${ }^{\mathrm{c} S n u} 17 \mathrm{p}-{ }^{\mathrm{c} B u d} 13 \mathrm{p}$ dimer, the affinity was partially recovered (Table $\mathbf{1}$ ). Only in the case of ${ }^{\mathrm{C}} \mathrm{Bud} 13 \mathrm{p}^{\mathrm{R} 237 \mathrm{~A}}$, the affinity towards the ${ }^{\mathrm{c} S n u} 17 \mathrm{p}-{ }^{\mathrm{c} P m l 1 p}$ dimer remained very low. Notably, although canonical UHMULM interactions depend on the conserved tryptophan ${ }^{22,23}$, cBud13p $\mathrm{p}^{\mathrm{W} 232 \mathrm{~A}}$ bound to the cSnu17p-cPmllp dimer with a $K_{\mathrm{d}}$ of $956.5 \pm$ $231.1 \mathrm{nM}$ (Fig. 3c,d). Taking into account that the assay can detect interactions with $K_{\mathrm{d}}$ values up to approximately $100 \mu \mathrm{M}$, differences in ${ }^{\mathrm{c}} \mathrm{Bud} 13 \mathrm{p}^{\mathrm{W} 232 \mathrm{~A}}$ binding to the ${ }^{c}$ Snu $17 \mathrm{p}$ monomer and the ${ }^{\mathrm{c} S n u} 17 \mathrm{p}-{ }^{\mathrm{c}} \mathrm{Pml} \mathrm{p}$ heterodimer reveal a cooperativity increase by more than 100 -fold.

To provide further evidence for the cooperative nature of REScomplex assembly, we analyzed binding properties of ${ }^{\mathrm{C}} \mathrm{Pmllp}$ to ${ }^{\mathrm{c} S n u} 17 \mathrm{p}$ heterodimers that were preassembled with ${ }^{\mathrm{c} B u d 13} \mathrm{p}$ mutants. ${ }^{\mathrm{c} P m l 1 p}$ bound to ${ }^{\mathrm{C}} \mathrm{S} n u 17 \mathrm{p}-{ }^{\mathrm{c}} \mathrm{Bud} 13 \mathrm{p}^{\mathrm{V} 235 \mathrm{~A}}$ with similar thermodynamic parameters as to the wild-type (WT) heterodimer.

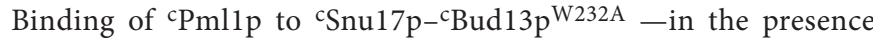
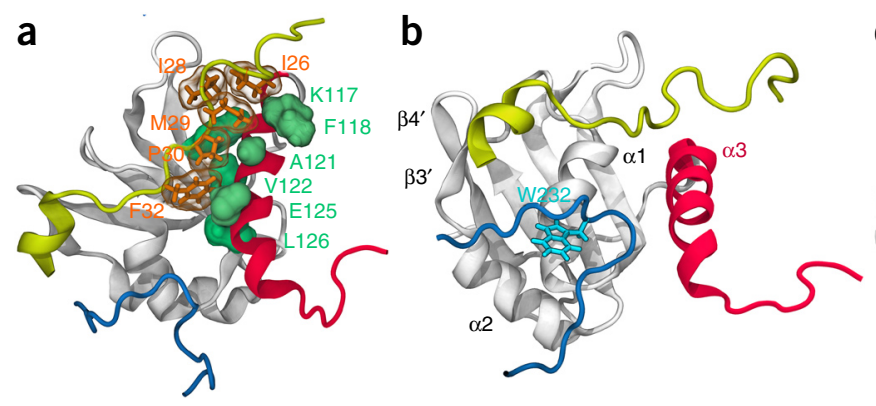

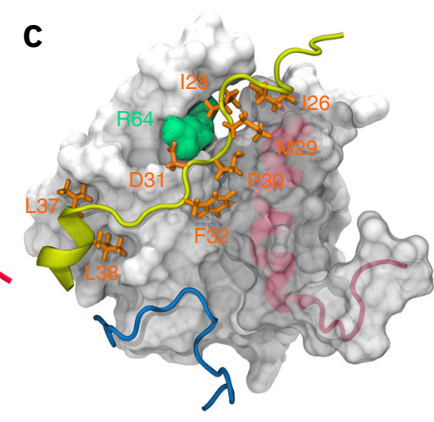

Figure 2 Interface between components of the RES core complex. (a) Interface between ${ }^{c P m l} 1 p$ and the $\mathrm{C}$-terminal $\alpha$-helix of cSnu17p (red). Orange, cPml1p residues; green, cSnu17p residues. (b) Interface formed by ${ }^{c}$ Bud $13 p$ (blue), ${ }^{c P m l} 1 p$ (yellow) and the C-terminal helix of ${ }^{c S n u 17 p ~(r e d), ~ h i g h l i g h t i n g ~ t h e ~}$ location of the side chain of W232 of ${ }^{c} B u d 13 p$. (c) Key interactions at the ${ }^{c S n u 17 p-c P m l 1 p ~ i n t e r f a c e . ~}$ Orange, ${ }^{c P m l 1 p}$ residues; green, $\mathrm{R} 64$ of ${ }^{c S n u 17 p}$, which forms a salt bridge with D31 of $\mathrm{CPml1p}$.

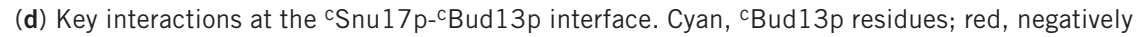
charged ${ }^{~} S$ Snu $17 p$ residues forming salt bridges with neighboring ${ }^{C B u d 13 p}$ arginines. (e) Detailed view of the trimer interface in RES between ${ }^{C B u d 13 p}$ (blue), cPml1p (yellow) and ${ }^{C S}$ nu17p (gray, red).
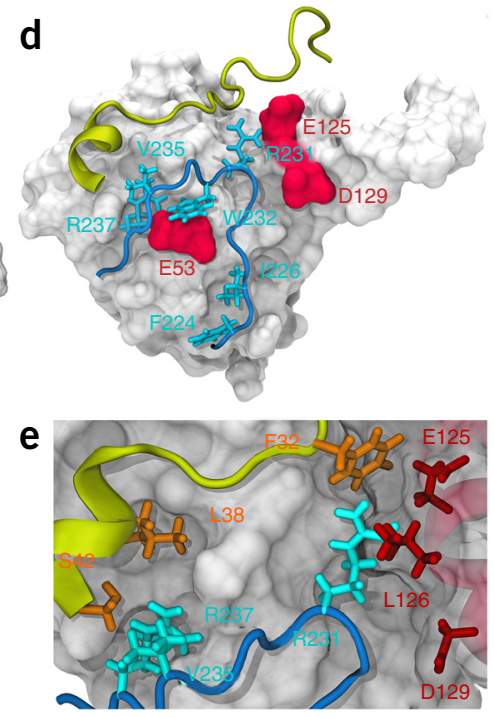
a

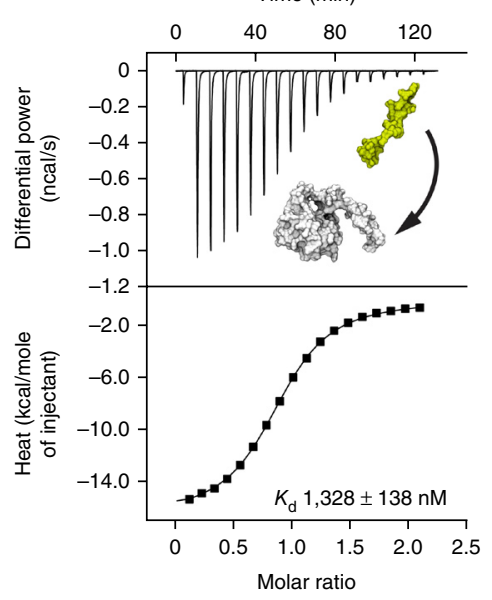

b

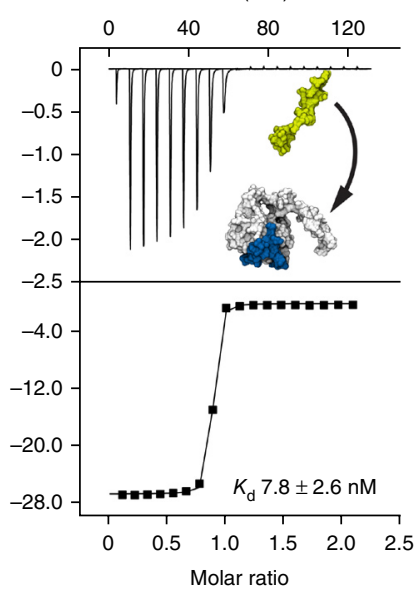

C

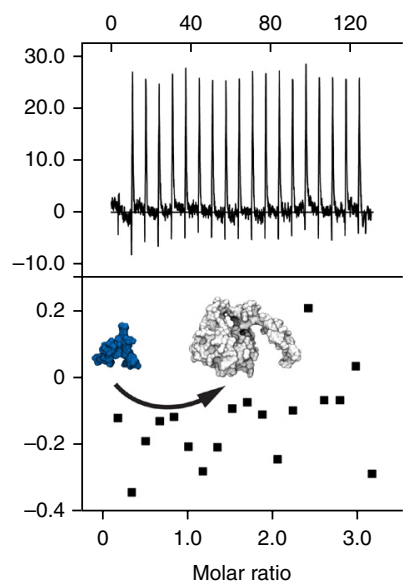

d

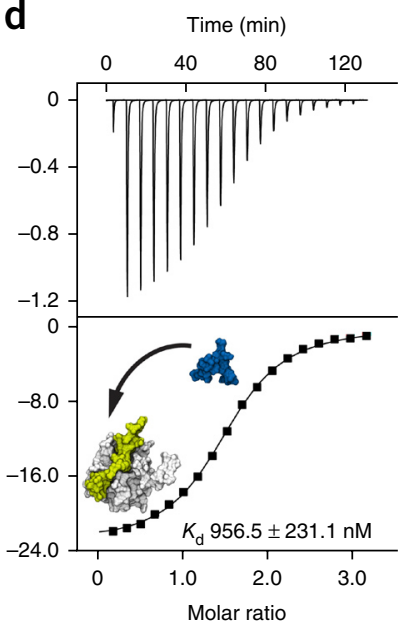

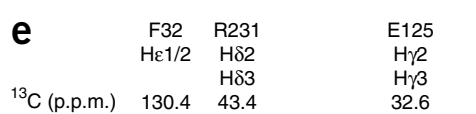

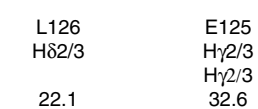

L126
$\mathrm{H} \delta 2 / 3$

\section{f}
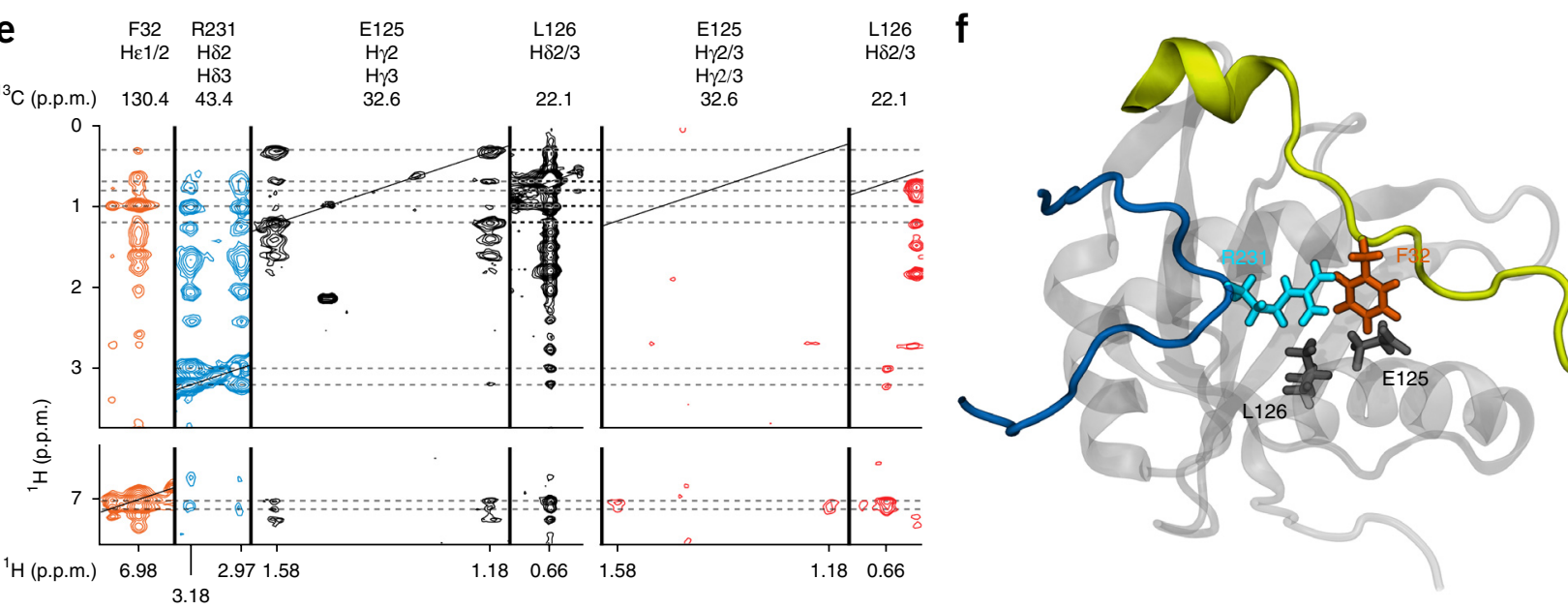

Figure 3 Assembly of the RES core complex is highly cooperative. (a-d) ITC binding studies between ${ }^{c} P m I 1 p$ and ${ }^{c} S n u 17 p$ (a), ${ }^{c} P m l 1 p$ and the

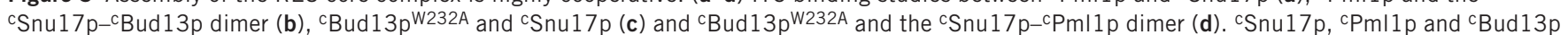
are shown in gray, yellow and blue, respectively. $K_{d}$ values are indicated. (e) Selected contacts from a ${ }^{13} \mathrm{C}$-edited NOESY-HSQC spectrum between E125 and L126 of ${ }^{\mathrm{C} S n u 17 p}$ (black), R231 of ${ }^{\mathrm{C} B u d 13 p}$ (cyan) and F32 of ${ }^{\mathrm{C} P m l 1 p}$ (orange) and the corresponding intermolecular NOE contacts (from E125 and L126) from a ${ }^{13} \mathrm{C}-15 \mathrm{~N}$ F1-filtered, ${ }^{13} \mathrm{C}$ F3-edited NOESY-HSQC spectrum (red). (f) Location of residues in the RES core structure for which intermolecular contacts are shown in e.

of excessive amounts of ${ }^{\mathrm{c}} \mathrm{Bud} 13 \mathrm{p}^{\mathrm{W} 232 \mathrm{~A}}$ - occurred with a slightly lower affinity than the wild-type interaction (Table 1). In contrast, the affinity of ${ }^{\mathrm{C}} \mathrm{Pml} 1 \mathrm{p}$ for ${ }^{\mathrm{C}} \mathrm{Snu} 17 \mathrm{p}-{ }^{\mathrm{C}} \mathrm{Bud} 13 \mathrm{p}^{\mathrm{R} 231 \mathrm{~A}}$ decreased from $7.8 \pm 2.6$ to $39.2 \pm 0.3 \mathrm{nM}$, consistently with the importance of the salt bridge between R231 of ${ }^{\mathrm{C} B u d 13 p}$, and both D129 and E125 of 'Snu17p (Figs. 2e and 3e,f). Finally, we investigated the interaction of ${ }^{\mathrm{C} m l 1 \mathrm{p} \text { and }}{ }^{\mathrm{c} B u d 13 p}$ with $\alpha 3$ of ${ }^{\mathrm{c} S}$ nu17p by alanine substitution of F32 in ${ }^{\mathrm{C}} \mathrm{Pml} 1 \mathrm{p}$ and R231 in ${ }^{\mathrm{C}} \mathrm{Bud13}$, both of which directly contact $\alpha 3$ of ${ }^{\mathrm{c} S}$ nu 17p (Fig. 2e). The mutations individually destabilized the interaction with ${ }^{\mathrm{C} S n u} 17 \mathrm{p}$, and their combination completely abolished assembly of the RES trimer (Table 1). In contrast, combination of ${ }^{\mathrm{C}} \mathrm{Pml} 1 \mathrm{p}^{\mathrm{F} 32 \mathrm{~A}}$ and ${ }^{\mathrm{C}} \mathrm{Bud} 13 \mathrm{p}^{\mathrm{W}} 232 \mathrm{~A}$ - bearing a mutation at W232, which is not in direct contact with $\alpha 3$ (Fig. 2e)-showed binding; however, this result is beyond straightforward $K_{\mathrm{d}}$ estimation. The cooperative recovery of even modest binding in the trimeric system is remarkable because both ${ }^{\mathrm{C}} \mathrm{Pml} 1 \mathrm{p}^{\mathrm{F} 32 \mathrm{~A}}$ and ${ }^{\mathrm{C}} \mathrm{Bud} 13 \mathrm{p}^{\mathrm{W} 232 \mathrm{~A}}$ did not bind to the 'Snu17p monomer individually.

RES-complex formation stabilizes the structure of Snu17p

The C-terminal $\alpha$-helix ( $\alpha 3$ ) extends the RRM fold of ${ }^{c}$ Snu $17 p$ and contacts ${ }^{\mathrm{C}} \mathrm{Pml} 1 \mathrm{p}$ and ${ }^{\mathrm{C}} \mathrm{Bud} 13 \mathrm{p}$ (Figs. 1 and 2 ). To address its role in RES assembly, we analyzed the conformation of cSnu17p in the heterodimeric complexes with ${ }^{\mathrm{C}} \mathrm{Bud} 13 \mathrm{p}$ and ${ }^{\mathrm{c} P m l 1 p}$ (Fig. 4). Analysis of the NMR chemical shifts by TALOS- ${ }^{24}$ revealed that the RRM fold of ${ }^{\mathrm{C}} \mathrm{Snu} 17 \mathrm{p}$ was retained in the two dimers (Fig. 4a). Moreover, $\alpha 3$

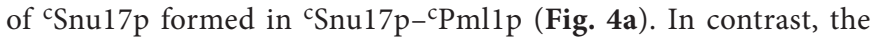
C-terminal region of 'Snu17p was mostly disordered in ${ }^{\mathrm{C}} \mathrm{Snu} 17 \mathrm{p}-$ ${ }^{\mathrm{c}}$ Bud13p (Fig. 4a). Only upon further addition of ${ }^{\mathrm{C}} \mathrm{Pmllp}$ did we observe large chemical-shift changes for residues 115-130 (Supplementary Figs. 1 and 3), a result suggesting that $\alpha 3$ of ${ }^{\mathrm{c}} \mathrm{S} n u 17 \mathrm{p}$ was stabilized. The region that forms $\alpha 3$ in the RES core complex is likely to be unfolded also in monomeric ${ }^{\mathrm{c} S} \mathrm{Sn} 17 \mathrm{p}$ because the NMR signal pattern of residues $115-132$ and $136-138$ in monomeric ${ }^{c} S n u 17 p$ was similar to that in the ${ }^{\mathrm{c} S}$ nu $17 \mathrm{p}-{ }^{\mathrm{c}} \mathrm{Bud} 13 \mathrm{p}$ dimer (Supplementary Fig. 1b).

To better understand the stabilizing role of binding of ${ }^{\mathrm{c}} \mathrm{Pmll} \mathrm{p}$ and ${ }^{\mathrm{C}} \mathrm{Bud} 13 \mathrm{p}$ to ${ }^{\mathrm{C} S}$ nu $17 \mathrm{p}$, we performed NMR hydrogen/deuterium $(\mathrm{H} / \mathrm{D})$ exchange experiments. Backbone amide protons of monomeric 'Snu17p exchanged rapidly after solubilization in $\mathrm{D}_{2} \mathrm{O}$, such that after the experimental dead time $(3 \mathrm{~min})$ we could detect only 11 residues with maximum half time of $17.7 \pm 1.2 \mathrm{~min}$ (fit \pm s.d.; Fig. $\mathbf{4 b}$ and Supplementary Fig. 4a). In the ${ }^{\mathrm{c} S n u} 17 \mathrm{p}-{ }^{\mathrm{c} B u d} 13 \mathrm{p}$ dimer, the maximum $\mathrm{H} / \mathrm{D}$ exchange time across all residues increased to 
Figure 4 Structural basis of the cooperative nature of the RES complex. (a) Residue-specific $\alpha$-helix content in 'Snu17p, calculated by TALOS- $\mathrm{N}^{24}$ on the basis of NMR chemical shifts observed for cSnu17p in the "Snu17p-cBud13p dimer (top), the 'Snu17-cPml1p dimer (bottom), and the ${ }^{C R E S}$ trimer (right). The region forming $\alpha$-helix 3 in the ${ }^{C R E S}$ trimer is shown in red. (b) Schematic representation of the folding-upon-binding mechanism that occurs during ${ }^{\mathrm{C}} \mathrm{RES}$-complex assembly. Yellow, ${ }^{c} P m I 1 p$; blue, 'Bud13p. The region forming $\alpha$-helix 3 in

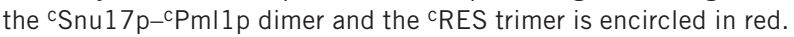
In monomeric ${ }^{\mathrm{C} S} \mathrm{nu} 17 \mathrm{p}$ and the ${ }^{\mathrm{C} S n u} 17 \mathrm{p}-{ }^{\mathrm{c} B} \mathrm{Bud} 13 \mathrm{p}$ dimer, this region is detached from the RRM fold and disordered with a weak helical propensity (schematically shown and encircled in red). Half-lives $\left(H / D^{1 / 2}\right)$ of $H / D$ exchange are color coded and mapped onto the corresponding structural model according to the color bar.

$307 \pm 21 \mathrm{~min}$, whereas in the ${ }^{\mathrm{c} S n u} 17 \mathrm{p}-{ }^{\mathrm{c}} \mathrm{Pml} 1 \mathrm{p}$ dimer it approached $2 \mathrm{~d}$. Remarkably, the RES core complex ( ${ }^{\mathrm{C}} \mathrm{RES}$ ) was further stabilized with $\mathrm{H} / \mathrm{D}$ exchange times exceeding $11 \mathrm{~d}$. Indeed, the amide proton of V58 did not show any detectable exchange after $16 \mathrm{~d}$. Solvent protection was not limited to the regions of steric hindrance (Fig. $\mathbf{4 b}$ and Supplementary Fig. 4a).

We provided further support for stabilization of the ${ }^{\mathrm{c} S n u} 17 \mathrm{p}$ structure upon heterodimerization and ${ }^{\mathrm{C}} \mathrm{RES}$ formation by ${ }^{15} \mathrm{~N}$ spin-relaxation measurements. For both the ${ }^{\mathrm{c} S n u} 17 \mathrm{p}-{ }^{\mathrm{c}} \mathrm{Pml} 1 \mathrm{p}$ dimer and the ${ }^{\mathrm{C}} \mathrm{RES}$ trimer, we detected no exchange contribution to the transverse relaxation, results indicating the absence of motions on the microsecond-to-millisecond timescale (Supplementary Fig. 4b). In the ${ }^{\mathrm{c} S n u} 17 \mathrm{p}-{ }^{\mathrm{c}} \mathrm{Bud}$ dimer, we observed an overall increase in ${ }^{15} \mathrm{~N}$ transverse relaxation rates, most probably because of the disordered and detached C-terminal helix increasing the overall rotational correlation time of this dimer. Beyond this overall increase, residues in the regions from I35 to I47 and A101 to K112 of ${ }^{\mathrm{c}} \mathrm{S}$ nu $17 \mathrm{p}$ showed increased ${ }^{15} \mathrm{~N}$ transverse relaxation rates caused by chemical exchange, results in agreement with the H/D exchange experiments for the ${ }^{c}$ Snu $17 p-{ }^{c}$ Bud dimer (Supplementary Fig. 4b). Monomeric ${ }^{\mathrm{c} S n u} 17 \mathrm{p}$ is not sufficiently stable through the durations and at the concentrations required for long NMR experiments.
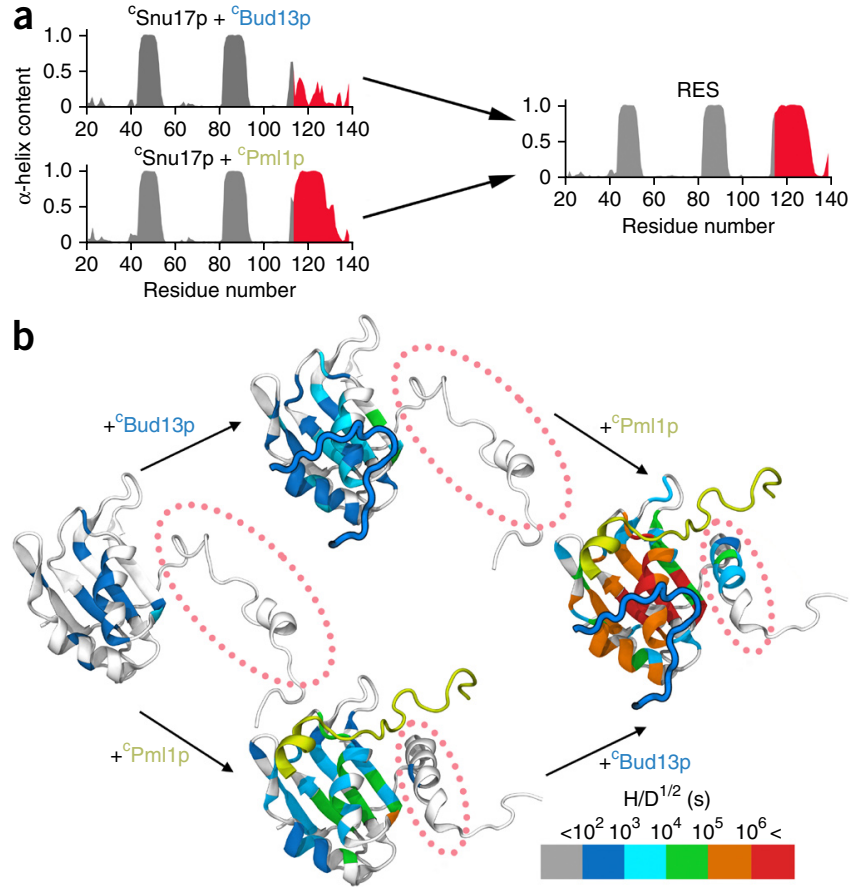

Analysis of ${ }^{15} \mathrm{~N}$ HSQC peak intensity versus ${ }^{1} \mathrm{H}$ line width in $2 \mathrm{D}$ HSQC spectra, however, demonstrated a large distribution of line-width values indicative of exchange broadening (Supplementary Fig. 4c). We observed a similar distribution in the case of the

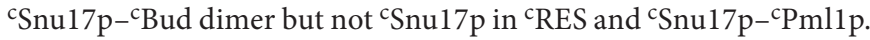
In addition, chemical shift-derived order parameters revealed a moderate increase upon heterotrimer formation (Supplementary Fig. 4d). Together, our results suggest that heterodimerization and trimer formation rigidify the ${ }^{\mathrm{C} S n u} 17 \mathrm{p}$ structure and provide a rationale for the strong cooperativity in the assembly of the RES core complex.

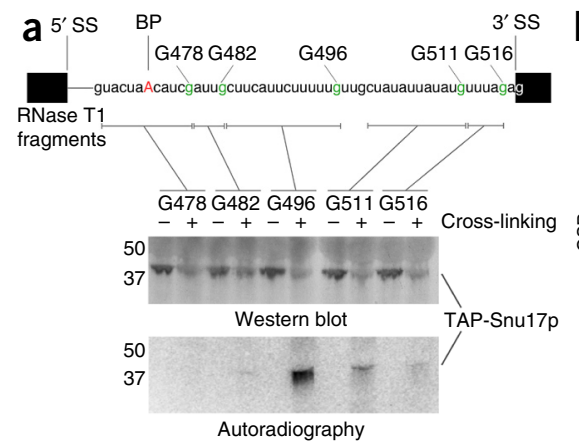

Figure 5 The ${ }^{\mathrm{C}} \mathrm{RES}$ complex binds to RNA. (a) Immunoprecipitation of Snu17p from UV cross-linked Bact $\Delta$ prp2 spliceosomal complexes (uncropped western blots in Supplementary Fig. 5c). Single $3^{\prime}-32 \mathrm{P}$-labeled Gs are indicated in green with their positions numbered. The $5^{\prime}$ and $3^{\prime}$ splice sites and branch point (5' SS, 3' SS and BP, respectively) are indicated. + and - indicate presence or absence of UV irradiation.

Top blot, immunoprecipitates identifying Snu17p-TAP in + lanes. Bottom blot, autoradiograph of the membrane, showing ${ }^{32}$ P-labeled actin pre-mRNA fragments. (b) Residue-specific chemical-shift perturbations (CSP) in ${ }^{~} S$ Snu $17 p$ upon titration of the RES core ('RES) complex with CUUCAUUCUUUUUG RNA. Gray, CSP $<1 \sigma$; pink, $1 \sigma<\mathrm{CSP}<2 \sigma$; light red, $2 \sigma<\mathrm{CSP}<3 \sigma$; red, $3 \sigma<\mathrm{CSP}$. Secondary-structure elements in ${ }^{~} S$ Snu17p are shown schematically at top. The locations of the RNA-recognition motifs RNP1 and RNP2 are marked. Helix $\alpha 3$ and the connecting loop are shown but are not part of the canonical RRM fold. (c) ${ }^{1} H_{-}{ }^{15} \mathrm{~N}$ HSQC spectra of free ${ }^{c} R E S$ (blue) and ${ }^{c} R E S$ in the presence of increasing amounts of CUUCAUUCUUUUUG (rainbow). (d) Chemical-shift changes shown in c, mapped onto the structure of the ${ }^{\mathrm{C} R E S}$ complex. ${ }^{C P m l} 1 p$ is shown in yellow. (e) Electrostatic potential mapped onto a molecular surface representation of the ${ }^{\mathrm{C} E S}$ complex; negative potential is in red and positive in blue with the cutoff set to $\pm 2 \mathrm{kT/eV}$. 
Figure 6 Structural comparison of the RES core complex to dimeric RRM complexes and human RES. (a-c) Structures of ${ }^{\mathrm{C}} \mathrm{RES}$ trimer (a), SPF45-SF3b155 (PDB 2PEH) ${ }^{21}$ (b) and p14-SFb155 (PDB 2FHO) ${ }^{33}$ (c). Yellow, cPml1p and p14; blue, 'Bud13p and SPF45; cyan, canonical tryptophan; red, C-terminal $\alpha$-helix of ${ }^{c}$ Snu17p. (d) Sequence alignment of ULM peptides. Cyan, canonical tryptophan; yellow, positively charged residues $\mathrm{N}$ terminal to the canonical tryptophan; green, serine residues. (e) Sequence alignment of ${ }^{\mathrm{C} B u d 13 p \text {, }}$ ${ }^{c} \mathrm{Pml} 1 \mathrm{p}$ and the C-terminal part of ${ }^{\mathrm{C} S n u 17 p}$ to their human orthologs. Red, identical residues; green, similar residues; blue, weakly differing residues; black dots, residues that contribute to the intermolecular interface within the RES core complex; red dots, residues that contribute to binding as evaluated by ITC.

\section{The RES core complex binds RNA}

RRMs (including Snu17p) contain two conserved amino acid sequences, RNP1 and RNP2, located on the central two $\beta$-strands that are important for canonical RNA binding ${ }^{25}$. We therefore tested whether Snu17p interacts with pre-mRNA in the context of native spliceosomes. Because RES-complex proteins were previously shown to be most abundant and stably bound in activated yeast spliceosomes $\left(B^{\text {act }}\right)^{26,27}$, we analyzed whether Snu17p contacts the pre-mRNA in purified $\mathrm{B}^{\text {act }}$ complexes. To this end, we generated a yeast strain carrying the prp2-1 mutation as well as a C-terminally tandem affinity purification (TAP)-tagged version of Snu17p. The prp2-1 muta-

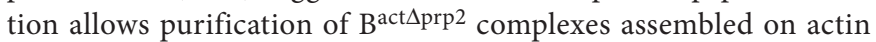
pre-mRNA ${ }^{28}$. Previous studies have indicated that the RES complex contacts U2 snRNP proteins ${ }^{4,12}$, suggesting that it might bind to the pre-mRNA in the vicinity of U2. In human spliceosomes, most U2 snRNP proteins bind to a region directly upstream of the branch site ${ }^{29}$, whereas in yeast only one U2 snRNP protein, Hsh155p, interacts with pre-mRNA between the branch point and the $3^{\prime}$ splice site ${ }^{30}$. To test a possibility of Snu 17 p interacting in this region we assembled $B^{\text {act } \Delta \text { prp2 }}$ complexes on site-specifically labeled pre-mRNAs that carried a single ${ }^{32} \mathrm{P}$ label directly $3^{\prime}$ of $\mathrm{G}$ nucleotides downstream of the branch site (Fig. 5a). Subsequently, we subjected them to UV cross-linking. After denaturation and digestion with RNase T1, which cleaves after G, we immunoprecipitated Snu17p with IgG beads and analyzed the immunoprecipitates by western blotting (Fig. 5a and Supplementary Fig. 5c) and autoradiography (Fig. 5a). Western blotting confirmed that Snu17p-TAP $(37 \mathrm{kDa})$ was indeed immunoprecipitated in all cases. However, we could see a strong radioactive band colocalizing with the western-blot signal solely in complexes assembled on the premRNA containing a $G$ nucleotide at position 496 . The complexes that assembled on pre-mRNAs carrying the ${ }^{32} \mathrm{P}$ label elsewhere showed no or very weak signals. Therefore we concluded that Snu17p, and thus the RES complex, directly interacts with the intron between the branch point and the $3^{\prime}$ splice site.

In order to obtain structural insight into the interaction of ${ }^{\mathrm{c}} \mathrm{RES}$ with this RNA-binding partner, we performed NMR chemical shiftperturbation experiments (Fig. 5b-d). RNA binding predominantly caused chemical-shift changes in the $\beta$-sheet and the adjacent loops of ${ }^{\mathrm{C}} \mathrm{Snu} 17 \mathrm{p}$ (Fig. 5d), which make up the most basic part of the ${ }^{\mathrm{c}} \mathrm{RES}$ (Fig. 5e). Most of the affected residues, such as Y34, I35, G36, N37, A75, Y76, L77 and K78, are conserved in RRMs. However, additional residues located in the C-terminal loop and $\alpha$-helix 3 also exhibited strong perturbation (Fig. 5b,d). These residues do not belong to the RNP1 and RNP2 motifs of Snu17p and are located between 9 and $20 \AA$ from those motifs. The observation that the same residues were also affected upon addition of ${ }^{\mathrm{C}} \mathrm{Pml} 1 \mathrm{p}$ to the ${ }^{\mathrm{c} S}$ nu $17 \mathrm{p}-{ }^{\mathrm{c}} \mathrm{Bud} 13 \mathrm{p}$ dimer (Supplementary Fig. 3c) suggests that the C-terminal $\alpha$-helix of ${ }^{\mathrm{S}} \mathrm{S} n \mathrm{17} \mathrm{p}$ has a role in RNA binding. We then examined the RNA affinity of monomeric ${ }^{\mathrm{c} S}$ nu $17 \mathrm{p}$, as well as ${ }^{\mathrm{c} S n u} 17 \mathrm{p}-{ }^{\mathrm{c}} \mathrm{Bud} 13 \mathrm{p}$ and ${ }^{\mathrm{c} S n u} 17 \mathrm{p}-{ }^{\mathrm{c}} \mathrm{Pmllp}$ dimers. The measurements demonstrated that RNA affinity increases along the ${ }^{c}$ RES assembly pathway from 496 to $126 \mu \mathrm{M}$ (Fig. 5b and Supplementary Fig. 5). Most of this increase was contributed by the presence of ${ }^{\mathrm{c} P m l 1 p}$. We then sought to confirm our findings by performing the same analysis but with RNA derived from an intron, which shows ${ }^{\mathrm{C}} \mathrm{RES}$-dependent splicing (TAN1) ${ }^{8}$. To this end, we designed a set of overlapping RNAs covering most of the aforementioned sequence (Supplementary Fig. 6a). Titrations led to results that were similar in terms of the ${ }^{\mathrm{c} S n u 17 p}$ interaction area but with more pronounced cooperativity (Supplementary Fig. 6b).

\section{DISCUSSION}

The solution NMR structure of the core of the heterotrimeric premRNA retention and splicing complex RES reveals how ${ }^{\mathrm{c}} \mathrm{Bud} 13 \mathrm{p}$ and ${ }^{c}$ Pmllp recognize the RRM domain of ${ }^{c}$ Snu17p (Figs. 1, 2 and 6a). Sequence homology of Bud13p to ligands that bind to U2AFhomology motifs of RRM domains suggested that Bud13p interacts with Snu17p according to canonical UHM-ULM interactions (Fig. 6b,d) ${ }^{13,15,16,18-22}$. However, the three-dimensional structure of the RES core complex demonstrated a distinct interaction mode unlike that of UHM and ULM (Fig. 6a). Consistently with the distinct ${ }^{\mathrm{C}} \mathrm{Bud} 13 \mathrm{p}-{ }^{\mathrm{c} S}$ nu $17 \mathrm{p}$ interaction, mutation of the W232 of ${ }^{\mathrm{c}} \mathrm{Bud} 13 \mathrm{p}$

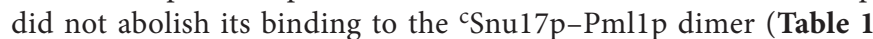
and Fig. 3c,d). Moreover, in vivo coproduction and purification of a Snu $17 \mathrm{p}-\mathrm{Bud} 13 \mathrm{p}^{\mathrm{W} 232 \mathrm{~A}}$ complex is possible ${ }^{13}$. In contrast, mutation of R237 eliminated the binding of ${ }^{\mathrm{C}} \mathrm{Bud} 13 \mathrm{p}$ to both monomeric ${ }^{\mathrm{c} S n u} 17 \mathrm{p}$ and ${ }^{\mathrm{C} S n u} 17 \mathrm{p}-{ }^{\mathrm{C}} \mathrm{Pml} 1 \mathrm{p}$ (Table 1), in agreement with the observation that R237 of ${ }^{\mathrm{C}} \mathrm{Bud} 13 \mathrm{p}$ forms a salt bridge with E53 of ${ }^{\mathrm{C}} \mathrm{S} n \mathrm{17} \mathrm{p}$ and is important for neutralizing the repulsion between W232 and E53 (Fig. 2d). In contrast, Bud13p might not only bind to Snu17p within the RES complex but also engage in interactions with other proteins, possibly via the canonical mode, in agreement with the ability of single ULMs to bind to different UHMs ${ }^{21,23}$.

Snu17p was suggested to be an ortholog of the human spliceosomal protein p14 (refs. 4,16,31), which binds to SF3b155 in the U2 snRNP-associated SF3b complex ${ }^{32,33}$. Comparison of the structure of the RES core complex with that of p14 bound to a SF3b155 peptide shows that ${ }^{\mathrm{C}} \mathrm{Pmllp}$ interacts with a different site on the RRM domain (Fig. 6a,c). In addition, ${ }^{\mathrm{C}} \mathrm{Pmllp}$ forces the C-terminal part 
of ${ }^{c}$ Snu $17 p$ to fold into an $\alpha$-helix (Figs. 1, 2 and 6a). Deletion of this region abolished binding of Pml1p to Snu17 $\mathrm{p}^{13,15}$. RRM extensions, as observed in Snu17p, are already folded in an RRM's free state ${ }^{34-36}$ or fold upon binding to RNA and protein ${ }^{32,33,37-39}$. For example, two short C-terminal helices of U1A provide an additional RNA interface for the interaction of its RRM domain with RNA ${ }^{36,40}$. Their position, however, is unlike the one found in the RES core complex.

The human orthologs of Pml1p, Bud13p and Snu17p are Snip1, hBud13p and RBMX2, respectively. Those orthologs contain several conserved residues that are important for RES-complex formation (Fig. 6e). In addition, hydrophobic residues of ${ }^{\mathrm{c} S n u} 17 \mathrm{p}$, such as V122 and L126, which interact with F32 of ${ }^{\mathrm{C}} \mathrm{Pml} 1 \mathrm{p}$ (Fig. 2a,e), are identical in Snu17p and RBMX2 (Fig. 6e). On a structural level, the C-terminal part of RBMX2 is predicted to adopt an $\alpha$-helical conformation similar to that of the C-terminal helix of Snu17p. The sequence conservation suggests that the molecular architecture of the RES core complex is conserved in humans.

Cooperativity plays an important part in the assembly of macromolecules, particularly in spliceosomal interaction networks ${ }^{2,41-44}$. Often, however, cooperativity is of the 'copy-and-enhance' type, in which multiple identical or similar units of low affinity act together to enable an elevated total affinity ${ }^{2,23}$. This mode of cooperativity is used in PUF60- and U2AF65-concomitant binding to SF3b155 to cooperatively recruit $\mathrm{U} 2 \mathrm{snRNP}^{44}$, as well as in splicing factor 1 and U2AF heterodimer association with the $3^{\prime}$ splice site ${ }^{43}$. In contrast, RES assembly is driven by conformational cooperativity, in which different proteins fold onto one another to allow efficient complex formation (Figs. 3 and 4): the affinity of ${ }^{\mathrm{C}} \mathrm{Pmllp}$ for the ${ }^{\mathrm{C}} \mathrm{S} n \mathrm{17} \mathrm{p}-$ ${ }^{\mathrm{c}} \mathrm{Bud} 13 \mathrm{p}$ dimer was more than two orders of magnitude higher than that for ${ }^{\mathrm{c} S n u} 17 \mathrm{p}$ alone (Fig. 3a,b). In addition, the W232A variant

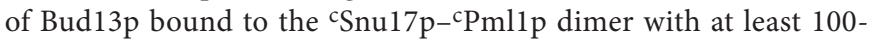
fold-higher affinity than to the ${ }^{\mathrm{c} S n u 17 p}$ monomer (Fig. 3c,d). Thus, cooperativity of RES-complex assembly is mutual, and each binding partner strongly enhances ${ }^{\mathrm{C} S}$ nu $17 \mathrm{p}$ binding of the other.

$\mathrm{H} / \mathrm{D}$ exchange rates, in combination with a variety of NMR dynamics parameters (Fig. 4 and Supplementary Fig. 4), suggest that the highly cooperative nature of RES assembly is caused by stabilization of the RRM fold of Snu17p upon binding of Bud13p and Pmllp (Fig. 4). 'Pmllp-induced folding of the C-terminal $\alpha$-helix of 'Snu17p provides further stabilization (Fig. 4). A similar cooperative mechanism is found in the KIX-MLL-cMyb heterotrimer ${ }^{45}$, in which a two-fold enhancement was linked to an MLL-induced enrichment of the population of the KIX conformer, which has high affinity for $\mathrm{cMyb}^{46}$.

We showed that the RES-complex protein Snu17p contacts premRNA in the region between the branch point and the $3^{\prime}$ splice site within a 14-nt-long RNA stretch upstream of the G nucleotide at position 496 (Fig. 5a). Previously, it has been shown that REScomplex proteins interact with U2 SF3b proteins ${ }^{12}$. By performing chemical protein-protein cross-linking studies with purified yeast $\mathrm{B}^{\text {act }}$ complexes, we recently were able to demonstrate direct interactions between Snu17p and Hsh155p (O. Dybkov, H. Urlaub and R.L., unpublished data). Because Hsh155p contacts nucleotides of the pre-mRNA between the branch point and $3^{\prime}$ splice site ${ }^{30}$, our observation that Snu $17 \mathrm{p}$ can be cross-linked to the same region is concordant with the topological neighborhood in the $\mathrm{B}^{\text {act }}$ spliceosome. The RES complex is required for efficient splicing of TAN1 pre-mRNA, and the intron sequence between the $5^{\prime}$ splice site and the branch point is necessary and sufficient to mediate RES dependency ${ }^{8}$. Our observation that Snu17p interacts with intron nucleotides downstream of the branch point does not conflict with this result because the requirement of TAN1 intron nucleotides upstream of the branch site for RES dependency could be an indirect effect.

We further showed that Snu17p in the RES trimer binds within $14 \mathrm{nt}$ from the $3^{\prime}$ end of actin pre-mRNA, where we could cross-link Snu17p in the context of the $B^{\text {act }}$ spliceosome. The affinity of the RES core complex for the RNA oligonucleotide was modest but within the reported range of affinities for other $\mathrm{RRMs}^{47,48}$. Moreover, in the context of the spliceosome, other factors may increase the RNA affinity of Snu17p. For example, Bud13p contains a conserved lysine-rich region that might bind to RNA. In addition, Pmllp or other non-RES proteins interacting with RES in the spliceosome, such as the U2 SF3b Hsh155p, might facilitate the recognition of RNA by RES, consistently with our finding that Snu17p can be cross-linked to pre-mRNA in purified $B^{\text {act }}$ spliceosomes (Fig. 5a). The unusual orientation of the C-terminal loop and $\alpha$-helix of Snu17p within the RNA-binding site suggests that the RES-RNA interaction is potentially another example of a noncanonical RRM-RNA recognition mode ${ }^{38-40,49-53}$. The increase in RNA affinity when ${ }^{\mathrm{C}} \mathrm{Pml} 1 \mathrm{p}$ is bound to ${ }^{\mathrm{c}} \mathrm{Snu} 17 \mathrm{p}$ and the C-terminal $\alpha$-helix of Snu17p is formed (Supplementary Fig. 5b) supports a noncanonical RRM-RNA recognition mode of RES. A recent study has suggested that cooperativity towards RNA binding in the spliceosome might be more pervasive than previously thought and could contribute to efficient and specific protein-RNA interactions ${ }^{54,55}$. In addition, the contribution of Pml1p-induced folding of Snu17p to RNA binding raises interesting questions about the biological function of Pml1p. Although Pmllp was previously suggested to be involved in pre-mRNA retention ${ }^{3,5}$, our data suggest that Pmllp could play a more direct part in the recognition of pre-mRNA during splicing.

In summary, the structure of the RES core complex revealed how an RRM domain arranges the binding of two protein ligands, ${ }^{c}$ Pmllp and ${ }^{c}$ Bud13p, through folding of the C-terminal $\alpha$-helix of 'Snu17p. In the spliceosome, the RES complex contacts pre-mRNA between the branch site and 3' splice site. The striking cooperativity of RES-complex formation and RNA binding highlights the importance of cooperative folding and binding in the functional organization of the spliceosome and, together with previously published data, establishes RES as a regulatory protein complex that links several aspects of pre-mRNA processing.

\section{METHODS}

Methods and any associated references are available in the online version of the paper.

Accession codes. Coordinates of the ${ }^{\mathrm{C}} \mathrm{RES}$ structure have been deposited in the Protein Data Bank under accession code 2MKC. The associated NMR data have been deposited with the Biological Magnetic Resource Bank under accession code 19766.

Note: Any Supplementary Information and Source Data files are available in the online version of the paper.

\section{ACKNOWLEDGMENTS}

This work was supported by the Deutsche Forschungsgemeinschaft (DFG) Collaborative Research Center 860 (project B2 to M.Z.) and the DFG Research Unit 806 (project A6 to M.C.W. and R.L.). We thank P. Fabrizio and K. Hartmuth for helpful discussions, T. Wandersleben for help with protein preparation and K. Giller for the preparation of expression constructs.

\section{AUTHOR CONTRIBUTIONS}

P.W. designed the project, conducted protein preparation and ITC and NMR data acquisition and analysis and wrote the paper; C.S. performed immunoprecipitation of Snu17p from spliceosomal complexes; S.X. performed NMR experiments; F.M. performed NMR data analysis; S.T. designed the project and conducted 
peptide arrays and protein preparation; M.C.W. designed and supervised the project and interpreted data; R.L. designed and supervised the project; S.B. designed and supervised the project; M.Z. designed and supervised the project and wrote the paper.

\section{COMPETING FINANCIAL INTERESTS}

The authors declare no competing financial interests.

Reprints and permissions information is available online at http://www.nature.com/ reprints/index.html.

1. Will, C.L. \& Luhrmann, R. Spliceosome structure and function. Cold Spring Harb. Perspect. Biol. 3, a3003707 (2011).

2. Brow, D.A. Allosteric cascade of spliceosome activation. Annu. Rev. Genet. 36, 333-360 (2002).

3. Dziembowski, A. et al. Proteomic analysis identifies a new complex required for nuclear pre-mRNA retention and splicing. EMBO J. 23, 4847-4856 (2004).

4. Gottschalk, A., Bartels, C., Neubauer, G., Luhrmann, R. \& Fabrizio, P. A novel yeast U2 snRNP protein, Snu17p, is required for the first catalytic step of splicing and for progression of spliceosome assembly. Mol. Cell. Biol. 21, 3037-3046 (2001).

5. Tuo, S., Nakashima, K. \& Pringle, J.R. Apparent defect in yeast bud-site selection due to a specific failure to splice the pre-mRNA of a regulator of cell-type-specific transcription. PLOS ONE 7, e47621 (2012).

6. Scherrer, F.W. Jr. \& Spingola, M. A subset of Mer1p-dependent introns requires Bud13p for splicing activation and nuclear retention. RNA 12, 1361-1372 (2006).

7. Schmidlin, T. et al. Single-gene deletions that restore mating competence to diploid yeast. FEMS Yeast Res. 8, 276-286 (2008).

8. Zhou, Y., Chen, C. \& Johansson, M.J. The pre-mRNA retention and splicing complex controls tRNA maturation by promoting TAN1 expression. Nucleic Acids Res. 41, 5669-5678 (2013).

9. Spingola, M., Armisen, J. \& Ares, M. Jr. Mer1p is a modular splicing factor whose function depends on the conserved U2 snRNP protein Snu17p. Nucleic Acids Res. 32, 1242-1250 (2004).

10. Hausmann, S. et al. Genetic and biochemical analysis of yeast and human cap trimethylguanosine synthase: functional overlap of 2,2,7-trimethylguanosine caps, small nuclear ribonucleoprotein components, pre-mRNA splicing factors, and RNA decay pathways. J. Biol. Chem. 283, 31706-31718 (2008).

11. Wang, Q. \& Rymond, B.C. Rds3p is required for stable U2 U2 snRNP recruitment to the splicing apparatus. Mol. Cell. Biol. 23, 7339-7349 (2003).

12. Wang, Q., He, J., Lynn, B. \& Rymond, B.C. Interactions of the yeast SF3b splicing factor. Mol. Cell. Biol. 25, 10745-10754 (2005).

13. Brooks, M.A. et al. Structure of the yeast Pml1 splicing factor and its integration into the RES complex. Nucleic Acids Res. 37, 129-143 (2009).

14. Jiang, M. et al. Genome-wide analysis of developmental and sex-regulated gene expression profiles in Caenorhabditis elegans. Proc. Natl. Acad. Sci. USA 98, 218-223 (2001).

15. Trowitzsch, S., Weber, G., Luhrmann, R. \& Wahl, M.C. An unusual RNA recognition motif acts as a scaffold for multiple proteins in the pre-mRNA retention and splicing complex. J. Biol. Chem. 283, 32317-32327 (2008).

16. Collinet, B. et al. Strategies for the structural analysis of multi-protein complexes: lessons from the 3D-Repertoire project. J. Struct. Biol. 175, 147-158 (2011).

17. Trowitzsch, S., Weber, G., Luhrmann, R. \& Wahl, M.C. Crystal structure of the Pml1p subunit of the yeast precursor mRNA retention and splicing complex. J. Mol. Biol. 385, 531-541 (2009).

18. Dinkel, H. et al. ELM: the database of eukaryotic linear motifs. Nucleic Acids Res. 40, D242-D251 (2012).

19. Korneta, I. \& Bujnicki, J.M. Intrinsic disorder in the human spliceosomal proteome. PLoS Comput. Biol. 8, e1002641 (2012).

20. Kielkopf, C.L., Rodionova, N.A., Green, M.R. \& Burley, S.K. A novel peptide recognition mode revealed by the $X$-ray structure of a core U2AF35/U2AF65 heterodimer. Cell 106, 595-605 (2001).

21. Corsini, L. et al. U2AF-homology motif interactions are required for alternative splicing regulation by SPF45. Nat. Struct. Mol. Biol. 14, 620-629 (2007).

22. Selenko, P. et al. Structural basis for the molecular recognition between human splicing factors U2AF65 and SF1/mBBP. Mol. Cell 11, 965-976 (2003).

23. Thickman, K.R., Swenson, M.C., Kabogo, J.M., Gryczynski, Z. \& Kielkopf, C.L. Multiple U2AF65 binding sites within SF3b155: thermodynamic and spectroscopic characterization of protein-protein interactions among pre-mRNA splicing factors. J. Mol. Biol. 356, 664-683 (2006).

24. Shen, Y. \& Bax, A. Protein backbone and sidechain torsion angles predicted from NMR chemical shifts using artificial neural networks. J. Biomol. NMR 56, 227-241 (2013).

25. Adam, S.A., Nakagawa, T., Swanson, M.S., Woodruff, T.K. \& Dreyfuss, G. mRNA polyadenylate-binding protein: gene isolation and sequencing and identification of a ribonucleoprotein consensus sequence. Mol. Cell. Biol. 6, 2932-2943 (1986).
26. Fabrizio, P. et al. The evolutionarily conserved core design of the catalytic activation step of the yeast spliceosome. Mol. Cell 36, 593-608 (2009).

27. Ohrt, T. et al. Prp2-mediated protein rearrangements at the catalytic core of the spliceosome as revealed by dcFCCS. RNA 18, 1244-1256 (2012).

28. Warkocki, Z. et al. Reconstitution of both steps of Saccharomyces cerevisiae splicing with purified spliceosomal components. Nat. Struct. Mol. Biol. 16, 1237-1243 (2009).

29. Gozani, O., Feld, R. \& Reed, R. Evidence that sequence-independent binding of highly conserved U2 snRNP proteins upstream of the branch site is required for assembly of spliceosomal complex A. Genes Dev. 10, 233-243 (1996).

30. McPheeters, D.S. \& Muhlenkamp, P. Spatial organization of protein-RNA interactions in the branch site- $3^{\prime}$ splice site region during pre-mRNA splicing in yeast. Mol. Cell. Biol. 23, 4174-4186 (2003).

31. Will, C.L. et al. A novel U2 and U11/U12 snRNP protein that associates with the pre-mRNA branch site. EMBO J. 20, 4536-4546 (2001).

32. Schellenberg, M.J. et al. Crystal structure of a core spliceosomal protein interface. Proc. Natl. Acad. Sci. USA 103, 1266-1271 (2006).

33. Kuwasako, K. et al. Complex assembly mechanism and an RNA-binding mode of the human p14-SF3b155 spliceosomal protein complex identified by NMR solution structure and functional analyses. Proteins 71, 1617-1636 (2008).

34. Martin-Tumasz, S., Richie, A.C., Clos, L.J. II, Brow, D.A. \& Butcher, S.E. A nove occluded RNA recognition motif in Prp24 unwinds the U6 RNA internal stem loop. Nucleic Acids Res. 39, 7837-7847 (2011).

35. Netter, C., Weber, G., Benecke, H. \& Wahl, M.C. Functional stabilization of an RNA recognition motif by a noncanonical $\mathrm{N}$-terminal expansion. RNA 15, 1305-1313 (2009).

36. Avis, J.M. et al. Solution structure of the N-terminal RNP domain of U1A protein: the role of $\mathrm{C}$-terminal residues in structure stability and RNA binding. J. Mol. Biol. 257, 398-411 (1996).

37. Golovanov, A.P., Hautbergue, G.M., Tintaru, A.M., Lian, L.Y. \& Wilson, S.A. The solution structure of REF2-I reveals interdomain interactions and regions involved in binding mRNA export factors and RNA. RNA 12, 1933-1948 (2006).

38. Cléry, A. et al. Molecular basis of purine-rich RNA recognition by the human SR-like protein Tra2- $\beta 1$. Nat. Struct. Mol. Biol. 18, 443-450 (2011).

39. Singh, M. et al. Structural basis for telomerase RNA recognition and RNP assembly by the holoenzyme La family protein p65. Mol. Cell 47, 16-26 (2012).

40. Weber, G., Trowitzsch, S., Kastner, B., Luhrmann, R. \& Wahl, M.C. Functional organization of the $\mathrm{Sm}$ core in the crystal structure of human U1 snRNP. EMBO J. 29, 4172-4184 (2010).

41. Varani, L. et al. The NMR structure of the $38 \mathrm{kDa}$ U1A protein-PIE RNA complex reveals the basis of cooperativity in regulation of polyadenylation by human U1A protein. Nat. Struct. Biol. 7, 329-335 (2000).

42. Williamson, J.R. Cooperativity in macromolecular assembly. Nat. Chem. Biol. 4, 458-465 (2008).

43. Berglund, J.A., Abovich, N. \& Rosbash, M. A cooperative interaction between U2AF65 and mBBP/SF1 facilitates branchpoint region recognition. Genes Dev. 12, 858-867 (1998).

44. Corsini, L. et al. Dimerization and protein binding specificity of the U2AF homology motif of the splicing factor Puf60. J. Biol. Chem. 284, 630-639 (2009).

45. De Guzman, R.N., Goto, N.K., Dyson, H.J. \& Wright, P.E. Structural basis for cooperative transcription factor binding to the CBP coactivator. J. Mol. Biol. 355, 1005-1013 (2006).

46. Brüschweiler, S. et al. Direct observation of the dynamic process underlying allosteric signal transmission. J. Am. Chem. Soc. 131, 3063-3068 (2009).

47. Hom, R.A. et al. Molecular mechanism of MLL PHD3 and RNA recognition by the Cyp33 RRM domain. J. Mol. Biol. 400, 145-154 (2010).

48. Cléry, A., Blatter, M. \& Allain, F.H. RNA recognition motifs: boring? Not quite. Curr. Opin. Struct. Biol. 18, 290-298 (2008).

49. Daubner, G.M., Clery, A. \& Allain, F.H. RRM-RNA recognition: NMR or crystallography. and new findings. Curr. Opin. Struct. Biol. 23, 100-108 (2013).

50. Daubner, G.M., Clery, A., Jayne, S., Stevenin, J. \& Allain, F.H. A syn-anti conformational difference allows SRSF2 to recognize guanines and cytosines equally well. EMBO J. 31, 162-174 (2012).

51. Oberstrass, F.C. et al. Structure of PTB bound to RNA: specific binding and implications for splicing regulation. Science 309, 2054-2057 (2005).

52. Tsuda, K. et al. Structural basis for the dual RNA-recognition modes of human Tra2-beta RRM. Nucleic Acids Res. 39, 1538-1553 (2011).

53. Cléry, A. et al. Isolated pseudo-RNA-recognition motifs of SR proteins can regulate splicing using a noncanonical mode of RNA recognition. Proc. Natl. Acad. Sci. USA 110, E2802-E2811 (2013).

54. Williams, S.G. \& Hall, K.B. Binding affinity and cooperativity control U2B"/snRNA/ U2A' RNP formation. Biochemistry 53, 3727-3737 (2014).

55. Williams, S.G. \& Hall, K.B. Linkage and allostery in snRNP protein/RNA complexes. Biochemistry 53, 3529-3539 (2014). 


\section{ONLINE METHODS}

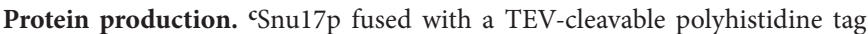
(HisTag) was produced in Escherichia coli BL21(DE3) cultivated at $37^{\circ} \mathrm{C}$ in LB medium (natural isotopic abundance) or $\mathrm{M} 9$ minimal medium with $\left[{ }^{15} \mathrm{~N}\right] \mathrm{H}_{4} \mathrm{Cl}$ and $\left[{ }^{13} \mathrm{C}\right]$ glucose (uniformly ${ }^{15} \mathrm{~N}-{ }^{13} \mathrm{C}-$ labeled ${ }^{\mathrm{c} S n u} 17 \mathrm{p}$ ). ${ }^{2} \mathrm{H}-{ }^{13} \mathrm{C}-{ }^{15} \mathrm{~N}$-labeled 'Snu17p was produced by first conditioning the $E$. coli precultures with increasing amounts of $\mathrm{D}_{2} \mathrm{O}(20 \%, 50 \%$ or $100 \%)$ in $\mathrm{M} 9$ minimal medium. After induction, the temperature was decreased to $27^{\circ} \mathrm{C}$, and cells were harvested after $25 \mathrm{~h}$. Cells were lysed by sonication in the base buffer $(50 \mathrm{mM}$ Tris, $300 \mathrm{mM} \mathrm{NaCl}$, and $1 \mathrm{mM}$ DTT, pH 7.5) with a mix of protease inhibitors (Complete-EDTA, Roche) and clarified by centrifugation. The resulting pellet was purified by three rounds of sequential resuspension and centrifugation in the neat base buffer, the base buffer supplemented with $2 \%$ Triton X-100, and finally the base buffer supplemented with $2 \mathrm{M} \mathrm{NaCl}$, and by subsequent immobilized metal-affinity chromatography (IMAC, Ni-NTA resin, Qiagen) under denaturing conditions with $6 \mathrm{M}$ guanidinium hydrochloride. The protein fractions were diluted to $10-20 \mu \mathrm{M}$ and refolded by dialysis against the base buffer supplemented with $0.4 \mathrm{M}$ arginine, $\mathrm{pH} 7.5$; this was followed by two rounds of dialysis against the base buffer. TEV protease was added, and the enzymatic cleavage was allowed to proceed until completion ( $4-5 \mathrm{~d}$ ). The reaction mixture was concentrated to $\sim 0.5 \mathrm{mM}$ and immediately purified via size-exclusion chromatography $(16 / 60$ Superdex 75) with NMR buffer ( $25 \mathrm{mM}$ sodium phosphate, $250 \mathrm{mM} \mathrm{NaCl}$ and $1 \mathrm{mM} \mathrm{NaN}_{3}, \mathrm{pH} 6.8$ ); this was followed by an additional dialysis against the same buffer. ${ }^{13} \mathrm{C}-{ }^{15} \mathrm{~N}$-labeled ${ }^{\mathrm{C}} \mathrm{Pml} \mathrm{p}$ and ${ }^{\mathrm{c}} \mathrm{Bud} 13 \mathrm{p}$ were biosynthesized in a manner similar to that for ${ }^{\mathrm{C}} \mathrm{Snu} 17 \mathrm{p}$. After IMAC with native conditions, the fusion protein was released by TEV and purified again by IMAC to remove the tag. Fractions containing peptides were freeze dried, resuspended in the minimum amount of water necessary, loaded onto a reverse-phase HPLC column, eluted with a gradient of $0-100 \%$ acetonitrile and $0.1 \%$ TFA, and freeze dried again. Mutant ${ }^{\mathrm{C} P m l 1 p}$ and ${ }^{\mathrm{C} B u d 13 p}$ peptides were purchased from EZbiolab. NMR samples of the ${ }^{\mathrm{c}} \mathrm{RES}$ trimer were prepared by mixture of ${ }^{\mathrm{c} S n u} 17 \mathrm{p},{ }^{\mathrm{C}} \mathrm{Bud} 13 \mathrm{p}$ and ${ }^{\mathrm{c} P m l 1} \mathrm{p}$ at a molar ratio of 1:1.2:1.5 and concentrated in Vivaspin 3-kDa-cutoff spin con-

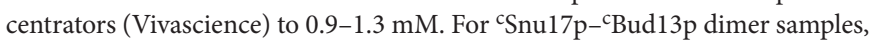
the ratio was 1:1.2, and in the case of the ${ }^{c S}$ nul $17 \mathrm{p}-{ }^{c} \mathrm{Pml} 1 \mathrm{p}$ dimer the molar ratio was 1:1.5, unless stated otherwise. For RDC measurements, samples of the ${ }^{\mathrm{c}} \mathrm{RES}$ trimer were prepared in which only ${ }^{\mathrm{c} S} \mathrm{Su} 17 \mathrm{p}$ or ${ }^{\mathrm{c} S} \mathrm{Sn} 17 \mathrm{p}$ and ${ }^{\mathrm{c} P m l 1 p}$, or only ${ }^{\mathrm{c} S n u} 17 \mathrm{p}$ and ${ }^{\mathrm{c}} \mathrm{Bud} 13 \mathrm{p}$ were ${ }^{13} \mathrm{C}$ and ${ }^{15} \mathrm{~N}$ labeled, and the remainder of peptides were at natural isotopic abundance. Alignment was achieved by the addition of buffer-exchanged Pf1 phage (ASLA Biotech).

Peptide arrays. Overlapping 15-, 20-, and 25-mer peptides covering amino acids 200-266 of Bud13p and 1-60 of Pmllp with single-residue offsets were synthesized and assembled as arrays on cellulose membranes (AG Molekulare Bibliotheken, Institut für Medizinische Immunologie, Charité-Universitätsmedizin Berlin). Membranes were washed with ethanol and SPOT-TBS $(2.7 \mathrm{mM} \mathrm{KCl}, 137 \mathrm{mM}$ $\mathrm{NaCl}$ and $50 \mathrm{mM}$ Tris- $\mathrm{HCl}, \mathrm{pH} 8.0)$, blocked for $3 \mathrm{~h}$ in blocking buffer $(2 \%$ $(\mathrm{w} / \mathrm{v})$ milk powder and $5 \%(\mathrm{w} / \mathrm{v})$ saccharose in SPOT-TBS) and again washed with SPOT-TBS. GST-Snu17p or GST alone were diluted in blocking buffer to a final concentration of $40 \mu \mathrm{g} / \mathrm{ml}$. Membranes were incubated overnight in protein solution at $4{ }^{\circ} \mathrm{C}$ on a shaker, washed with SPOT-TBS, incubated with rabbit anti-GST antibody (Santa Cruz Biotechnology; 1:1,000 in blocking buffer) for $3 \mathrm{~h}$ and, after being washed with SPOT-TBS, were incubated with horseradish peroxidase-conjugated goat anti-rabbit IgG (Jackson ImmunoResearch; 1:25,000 in blocking buffer) for $1.5 \mathrm{~h}$. Validation information for both antibodies is available on the manufacturers' websites. After being washed with SPOTTBS, membranes were developed with the Western Lightning Plus ECL system (PerkinElmer). Chemiluminescence was detected on a STELLA high-sensitivity modular imaging system (Raytest) and analyzed with the Advanced Image Data Analyzer software.

NMR spectroscopy. NMR experiments were performed on 600-, 700-, 800- and 900-MHz spectrometers (Bruker) equipped with cryogenic or room-temperature probes at $35^{\circ} \mathrm{C}$. Sequence-specific assignment of backbone resonances of ${ }^{c} \mathrm{RES}$,

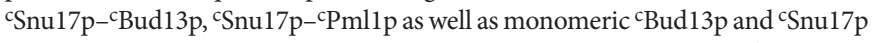
was achieved through 3D HNCA, HNCOCA, HNCACB, HNCO and ${ }^{15} \mathrm{~N}$-edited NOESY-HSQC experiments ${ }^{56}$. For the side chain assignment of the three subunits in the ${ }^{\mathrm{R} E S}$ trimer $3 \mathrm{D}$ HcCH-TOCSY, HBCBCGCDHD, and aliphatic and aromatic ${ }^{13} \mathrm{C}$-edited NOESY-HSQC were recorded ${ }^{56-58}$. Intermolecular contacts were extracted from three ${ }^{13} \mathrm{C}-{ }^{15} \mathrm{~N}$ F1-filtered $/{ }^{13} \mathrm{C}$ F3-edited NOESY-HSQC experiments recorded on ${ }^{\mathrm{C}} \mathrm{RES}$ trimer samples in which ${ }^{\mathrm{C} S n u 17} \mathrm{p}$, ${ }^{\mathrm{C} B u d 13 p}$ or ${ }^{9}$ Pmllp was ${ }^{13} \mathrm{C}-{ }^{15} \mathrm{~N}$ labeled, and the other two subunits were at natural abundance ${ }^{59}$. Additional contacts were observed in a ${ }^{13} \mathrm{C}$ F1-edited $/{ }^{13} \mathrm{C}-{ }^{15} \mathrm{~N}$ F3-filtered HSQC-NOESY experiment recorded on a ${ }^{c}$ RES trimer sample in which only ${ }^{\mathrm{c} P m l 1 p}$ was ${ }^{13} \mathrm{C}-{ }^{15} \mathrm{~N}$ labeled ${ }^{59}$. All NOESY experiments were run with a mixing time of $120 \mathrm{~ms}$. Spectra were processed with Topspin (Bruker) and NMRPipe ${ }^{60}$ and analyzed with ccpnmr Analysis 2.2.1. (ref. 61).

For RNA titrations, the ${ }^{\mathrm{R}} \mathrm{RES}$ trimer and the RNAs were dialyzed against $25 \mathrm{mM}$ sodium phosphate, and $75 \mathrm{mM} \mathrm{NaCl}, \mathrm{pH}$ 6.8. The ${ }^{\mathrm{c}} \mathrm{RES}$ trimer, in which only ${ }^{\mathrm{c} S n u} 17 \mathrm{p}$ was ${ }^{15} \mathrm{~N}$ labeled, was concentrated to $100 \mu \mathrm{M}$. A reference and three titration points were collected. For estimation of binding affinities of RNA (CUUCAUUCUUUUUG and ACGAAUUAGA) for four members of the ${ }^{\mathrm{c}} \mathrm{RES}$ assembly pathway, a similar procedure was followed with $50 \mu \mathrm{M}$ of ${ }^{\mathrm{C} S n u 17 p}$ and one reference spectrum and six titration points. Binding of RNA was followed in $2 \mathrm{D}^{1} \mathrm{H}_{-}{ }^{15} \mathrm{~N}$ HSQC spectra. Averaged ${ }^{1} \mathrm{H}_{-}{ }^{15} \mathrm{~N}$ chemical-shift perturbation between the free and RNA-bound states (CSP) was calculated according to $\left[\left(0.14 \delta_{\mathrm{N}}\right)^{2}+\left(\delta_{\mathrm{H}}\right)^{2}\right]^{1 / 2}$. Subsequently the values were either normalized on the basis of the CSP of R110 and K138 according to $\left(\mathrm{CSP}-\mathrm{CSP}_{138}\right) /\left(\mathrm{CSP}_{110}-\right.$ $\mathrm{CSP}_{138}$ ) or, for the affinity estimation, left unchanged. Binding curves were fit according to $\operatorname{CSP}(x)=\operatorname{CSP}_{\max }\left(\left(\left[{ }^{c} S n u 17 \mathrm{p}\right]+x+K_{\mathrm{d}}\right)-\left(\left(\left[{ }^{\mathrm{C} S} \operatorname{Sn} 17 \mathrm{p}\right]+x+K_{\mathrm{d}}\right)^{2}-\right.\right.$ $4\left[{ }^{\mathrm{C} S}\right.$ nu $\left.\left.17 \mathrm{p}\right] x\right)^{1 / 2} /\left(2\left[{ }^{\mathrm{c} S}\right.\right.$ nu $\left.\left.17 \mathrm{p}\right]\right)$.

HN and NCO RDCs were measured with BSD-IPAP-HSQC and $\mathrm{HN}(\alpha / \beta-\mathrm{NCo}-\mathrm{J})$ experiments, respectively, on isotropic and aligned samples ${ }^{62,63}$. Residues in flexible regions and overlapped and low-intensity peaks were excluded from the analysis, thus resulting in a total of $68 \mathrm{NCO}\left({ }^{c}\right.$ Snul $\left.7 \mathrm{p}\right), 82 \mathrm{HN}$ ( ${ }^{\mathrm{C} S n u 17 p}+{ }^{\mathrm{C} P m l 1 p}$ ) and $90 \mathrm{HN}$ ('S Snu17p + ${ }^{\mathrm{C} B u d 13 p}$ ) RDCs. RDCs were fit to the structure of ${ }^{\mathrm{C}} \mathrm{RES}$ before and after RDC refinement with PALES ${ }^{64}$.

${ }^{15} \mathrm{~N}$ transverse relaxation rate $R_{2}$ (with a single refocusing pulse) and $R_{1 \rho}$ (3.5-kHz spin-lock field) spin relaxation experiments were recorded at $20^{\circ} \mathrm{C}$ on samples containing ${ }^{\mathrm{C} S}$ Snu $17 \mathrm{p}-{ }^{\mathrm{C} P m l 1 p}$ dimer, ${ }^{\mathrm{C} S}$ Snu17p-cBud13p dimer and ${ }^{\mathrm{C}} \mathrm{RES}$. Seven to ten delays up to $100 \mathrm{~ms}$ were collected, and data were fit with Ccpnmr Analysis. Errors were estimated according to a covariance matrix analysis. Owing to the high spin-lock field, offset errors (the highest offset $<800 \mathrm{~Hz}$ ) in $\mathrm{R}_{1 \rho}$-to- $\mathrm{R}_{2}$ conversion were neglected, and $R_{1 \rho}$ was assumed to estimate $R_{2}$ according to ref. 65. The apparent exchange contribution, $R_{e x}$, was then estimated as the difference between $R_{2}$ and $R_{1 \rho}$. Analysis of monomeric ${ }^{c}$ Snu17p was not possible, owing to aggregation and precipitation, which occurred during long experiments at the required concentrations.

${ }^{1} \mathrm{H}-{ }^{15} \mathrm{~N}$ HSQC spectra, which were collected on all four members of the ${ }^{c}$ RES assembly pathway and processed without weighing function, were used for line-shape analysis. Cross-peak intensities were normalized to the flexible C-terminal residue (K138).

H/D exchange. Hydrogen-deuterium exchange analysis was performed by freeze drying samples of ${ }^{\mathrm{c}} \mathrm{RES}$, ${ }^{\mathrm{c}}$ Snu $17 \mathrm{p}-{ }^{\mathrm{c} P m l 1 p}$ dimer, ${ }^{\mathrm{C} S}$ nu $17 \mathrm{p}-{ }^{\mathrm{c} B u d 13 p}$ dimer and 'Snu17p monomer (25 $\mathrm{mM}$ sodium phosphate, $250 \mathrm{mM} \mathrm{NaCl}$, and $1 \mathrm{mM} \mathrm{NaN}_{3}$, $\mathrm{pH} 6.8$ ) and subsequent solubilization of the freeze-dried protein in either $10 \%$ or $100 \% \mathrm{D}_{2} \mathrm{O}$. The $10 \% \mathrm{D}_{2} \mathrm{O}$ served as a reference and confirmed that freeze drying did not perturb the structure. The SOFAST-HMQC pulse sequence was used to maximize the (signal/noise)/time ratio ${ }^{66}$. The dead time of the experiment was $3 \mathrm{~min}$, and the acquisition time was $6 \mathrm{~min} .55$ successive HMQC experiments were collected $(\sim 5.5 \mathrm{~h})$ at a temperature of $20^{\circ} \mathrm{C}$. Owing to some slowly exchang-

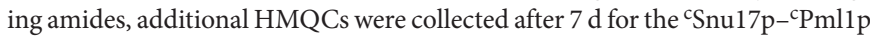
dimer and after 7, 16 and $17 \mathrm{~d}$ for ${ }^{\mathrm{C}} \mathrm{RES}$. Peak intensities were fit to a single exponential-decay function with Ccpnmr Analysis ${ }^{61}$. Reported errors are errors of the fit.

Structure calculation. The structure of the ${ }^{\mathrm{c}}$ RES complex was calculated with CYANA 3.0 (ref. 67). The three chains were connected by flexible linkers with zero van der Waals radii. The maximum upper distance limit was set to $6.5 \AA$ and the reference distance to $4.25 \AA$. Structural calculations were supplemented by dihedral-angle restraints that were derived from backbone chemical shifts with DANGLE ${ }^{61}$. Eight cycles of structure calculation combined with automatic NOE assignment were carried out. Intermolecular NOE contacts in filtered/ edited NOESY experiments were assigned manually and were kept fixed 
during the calculation. Hydrogen bonds in $\alpha$-helices and $\beta$-sheets were identified from this ensemble in combination with characteristic NOE patterns and were subsequently included into the structure calculation. From the final 100 structures, the 20 lowest-energy structures were selected and refined in CNS with the water RECOORD script ${ }^{68}$. RDC refinement was carried out in Xplor-NIH 2.34 with standard procedures ${ }^{69}$. Figures were prepared with $\mathrm{VMD}^{70}$ and PyMOL (http://www.pymol.org/). The structure that has the lowest r.m.s.d. value to the mean structure was used to represent the ensemble. Electrostatic potentials were analyzed with APBS with cutoffs set to $\pm 2 \mathrm{kT} / \mathrm{eV}$ (ref. 71).

Isothermal titration calorimetry. ITC measurements were performed on a VP-ITC instrument (Microcal). ' ${ }^{\mathrm{S}}$ nu17p, ${ }^{\mathrm{C}} \mathrm{Pml} 1 \mathrm{p}$ and ${ }^{\mathrm{C}} \mathrm{Bud} 13 \mathrm{p}$ and their mutants were dialyzed against NMR buffer $(25 \mathrm{mM}$ sodium phosphate, $250 \mathrm{mM} \mathrm{NaCl}$, and $1 \mathrm{mM} \mathrm{NaN}_{3}, \mathrm{pH}$ 6.8). Measurements were performed at $2{ }^{\circ} \mathrm{C}$ by titration of 10 - to 20 -fold molar excess of ${ }^{\mathrm{C}} \mathrm{Pmll} p$ or ${ }^{\mathrm{C}} \mathrm{Bud} 13 \mathrm{p}$ (or their mutants) to free ${ }^{\mathrm{C} S n u 17 p}$ or either ${ }^{\mathrm{C} S n u} 17 \mathrm{p}$ with two-fold molar excess of ${ }^{\mathrm{C}} \mathrm{Pml} 1 \mathrm{p}$ (or its mutants) or ${ }^{\mathrm{C} S} \mathrm{Sn} 17 \mathrm{p}$ with 1.5 -fold molar excess of ${ }^{\mathrm{c}} \mathrm{Bud} 13 \mathrm{p}$ (or its mutants). In the case of the titrations of ${ }^{\mathrm{P}} \mathrm{Pml} 1 \mathrm{p}$ and ${ }^{\mathrm{C}} \mathrm{Pml} 1 \mathrm{p}^{\mathrm{F} 32 \mathrm{~A}}$ to the ${ }^{\mathrm{C} S} \mathrm{~S} u 17 \mathrm{p}-{ }^{\mathrm{C}} \mathrm{Bud} 13 \mathrm{p}^{\mathrm{W}}{ }^{232 \mathrm{~A}}$ dimer, ${ }^{\mathrm{C} B u d} 13 \mathrm{p}^{\mathrm{W}} 232 \mathrm{~A}$ was present in five-fold molar excess. ${ }^{C}$ Bud $13 \mathrm{p}^{\mathrm{W} 232 \mathrm{~A}}$ does not bind to monomeric ${ }^{\mathrm{c} S} \mathrm{Su} 17 \mathrm{p}$, but as soon as ${ }^{\mathrm{C}} \mathrm{Pmll} \mathrm{p}$ is added, mutual cooperativity drives the binding of excess of ${ }^{\mathrm{C} B u d 13} \mathrm{p}^{\mathrm{W} 232 \mathrm{~A}}$, and this in turn enhances ${ }^{\mathrm{C}} \mathrm{Pml} 1 \mathrm{p}$ affinity. Thus, the measurement returns a binding curve with a shape corresponding to ${ }^{\mathrm{C} m l 1 \mathrm{p}}$ binding, with $\Delta S$ and $\Delta H$ reporting on both events. The cSnu17p concentration varied from 10 to $20 \mu \mathrm{M}$. A sequence of 20 injections of $15 \mu \mathrm{L}$ every 5 min was used. Control measurements were taken by titration of either the peptides to buffer and buffer to free ${ }^{c} S n u 17 p$ or any of the mentioned dimers. Heats of dilution were negligible and comparable to the plateau part of thermograms. Heats of dilution were subtracted from binding thermograms before being fit to a singlesite binding model. At least two repeats for each quantifiable binding titration were performed; results were averaged, and the error reported is the difference between the two extreme values. If no reliable fitting could be performed, the approximate fit is shown to indicate that binding takes place.

Immunoprecipitation of Snu17p from cross-linked $B^{\text {act } \Delta p r p 2}$ spliceosomal complexes. A yeast strain carrying the prp2-1 mutation ${ }^{72}$ and a C-terminally TAP-tagged Snu17p was created as described in ref. 73. In this extract, yeast $\mathrm{B}^{\text {act } \Delta \text { prp2 }}$ spliceosomal complexes were assembled and purified as described in ref. 28 on site-specifically ${ }^{32} \mathrm{P}$-labeled pre-mRNA. The pre-mRNA was produced by DNA splint-directed RNA ligation ${ }^{74}$ of RNA fragments obtained by sitespecific DNA enzyme cleavage ${ }^{75}$ of in vitro-transcribed actin pre-mRNA. Approximately $1 \mathrm{pmol}$ of spliceosomes were eluted in $400 \mu \mathrm{l} \mathrm{GK75}(75 \mathrm{mM} \mathrm{KCl}$, $20 \mathrm{mM}$ HEPES-KOH, pH 7.9, $1.5 \mathrm{mM} \mathrm{MgCl}_{2}, 0.01 \% \mathrm{NP}-40$, and $5 \%$ glycerol) and subjected to UV cross-linking at a 254-nm wavelength for $1 \mathrm{~min}$. The complexes were first precipitated with $\mathrm{EtOH}$ and then were denatured by incubation with $3 \%$ SDS in NET buffer $\left(150 \mathrm{mM} \mathrm{NaCl}\right.$, and $50 \mathrm{mM}$ Tris, $\mathrm{pH} \mathrm{7.5)}$ at $70^{\circ} \mathrm{C}$ for $10 \mathrm{~min}$. After 1:20 dilution with NET buffer, the RNA was digested with a final concentration of 6 units/ $\mu$ l RNAse T1 (Ambion) at $37^{\circ} \mathrm{C}$ for $1 \mathrm{~h}$. Snu17p-TAP was immunoprecipitated directly from the digestion reaction, essentially as described in ref. 76. Proteins were eluted from the IgG beads (GE Healthcare) by addition of $1 \times$ NuPAGE LDS sample buffer (Invitrogen) and incubation at $70^{\circ} \mathrm{C}$ for $10 \mathrm{~min}$, and were separated on Novex NuPAGE gels (Invitrogen). Western blotting was performed with peroxidase-anti-peroxidase complex (PAP, Sigma). After transfer, but prior to Western blotting, the membrane was subjected to autoradiography.

56. Sattler, M., Schleucher, J. \& Griesinger, C. Heteronuclear multidimensional NMR experiments for the structure determination of proteins in solution employing pulsed field gradients. Prog. Nucl. Magn. Reson. Spectrosc. 34, 93-158 (1999).

57. Yamazaki, T., Forman-Kay, J.D. \& Kay, L.E. Two-dimensional NMR experiments for correlating ${ }^{13} \mathrm{C} \beta$ and ${ }^{1} \mathrm{H} \delta / \varepsilon$. chemical shifts of aromatic residues in $13 \mathrm{C}$-labeled proteins via scalar couplings. J. Am. Chem. Soc. 115, 11054-11055 (1993).

58. Bax, A., Clore, G.M. \& Gronenborn, A.M. ${ }^{1} \mathrm{H}-{ }^{1} \mathrm{H}$ correlation via isotropic mixing of ${ }^{13} \mathrm{C}$ magnetization, a new three-dimensional approach for assigning ${ }^{1} \mathrm{H}$ and ${ }^{13} \mathrm{C}$ spectra of ${ }^{13}$ C-enriched proteins. J. Magn. Reson. 88, 425-431 (1990).

59. Zwahlen, C. et al. Methods for measurement of intermolecular NOEs by multinuclear NMR spectroscopy: application to a bacteriophage $\lambda$ N-peptide/boxB RNA complex. J. Am. Chem. Soc. 119, 6711-6721 (1997).

60. Delaglio, F. et al. NMRPipe: a multidimensional spectral processing system based on UNIX pipes. J. Biomol. NMR 6, 277-293 (1995).

61. Vranken, W.F. et al. The CCPN data model for NMR spectroscopy: development of a software pipeline. Proteins 59, 687-696 (2005).

62. Yao, L., Ying, J. \& Bax, A. Improved accuracy of ${ }^{15} \mathrm{~N}-1 \mathrm{H}$ scalar and residual dipolar couplings from gradient-enhanced IPAP-HSQC experiments on protonated proteins. J. Biomol. NMR 43, 161-170 (2009).

63. Permi, P., Heikkinen, S., Kilpelainen, I. \& Annila, A. Measurement of ${ }^{1} \mathrm{~J}_{\mathrm{NC}}$ and $2 \mathrm{~J}_{\mathrm{H}} \mathrm{N}_{\mathrm{C}^{\prime}}$ couplings from spin-state-selective two-dimensional correlation spectrum. J. Magn. Reson. 140, 32-40 (1999).

64. Zweckstetter, M. NMR: prediction of molecular alignment from structure using the PALES software. Nat. Protoc. 3, 679-690 (2008).

65. Pagano, K. et al. Direct and allosteric inhibition of the FGF2/HSPGs/FGFR1 ternary complex formation by an antiangiogenic, thrombospondin-1-mimic small molecule. PLOS ONE 7, e36990 (2012).

66. Schanda, P., Kupce, E. \& Brutscher, B. SOFAST-HMQC experiments for recording two-dimensional heteronuclear correlation spectra of proteins within a few seconds. J. Biomol. NMR 33, 199-211 (2005).

67. Güntert, P., Mumenthaler, C. \& Wuthrich, K. Torsion angle dynamics for NMR structure calculation with the new program DYANA. J. Mol. Biol. 273, 283-298 (1997).

68. Nederveen, A.J. et al. RECOORD: a recalculated coordinate database of 500+ proteins from the PDB using restraints from the BioMagResBank. Proteins 59, 662-672 (2005).

69. Schwieters, C.D., Kuszewski, J.J., Tjandra, N. \& Clore, G.M. The Xplor-NIH NMR molecular structure determination package. J. Magn. Reson. 160, 65-73 (2003).

70. Humphrey, W., Dalke, A. \& Schulten, K. VMD: visual molecular dynamics. J. Mol. Graph. 14, 33-38 (1996).

71. Baker, N.A., Sept, D., Joseph, S., Holst, M.J. \& McCammon, J.A. Electrostatics of nanosystems: application to microtubules and the ribosome. Proc. Natl. Acad. Sci. USA 98, 10037-10041 (2001).

72. Yean, S.L. \& Lin, R.J. U4 small nuclear RNA dissociates from a yeast spliceosome and does not participate in the subsequent splicing reaction. Mol. Cell. Biol. 11, 5571-5577 (1991).

73. Puig, 0 . et al. The tandem affinity purification (TAP) method: a general procedure of protein complex purification. Methods 24, 218-229 (2001).

74. Moore, M.J. \& Sharp, P.A. Site-specific modification of pre-mRNA: the 2'-hydroxyl groups at the splice sites. Science 256, 992-997 (1992).

75. Silverman, S.K. \& Baum, D.A. Use of deoxyribozymes in RNA research. Methods Enzymol. 469, 95-117 (2009).

76. Urlaub, H., Hartmuth, K., Kostka, S., Grelle, G. \& Luhrmann, R. A general approach for identification of RNA-protein cross-linking sites within native human spliceosomal small nuclear ribonucleoproteins (snRNPs). Analysis of RNA-protein contacts in native U1 and U4/U6.U5 snRNPs. J. Biol. Chem. 275, 41458-41468 (2000). 